\title{
A Monte Carlo uncertainty analysis of ozone trend predictions in a two dimensional model
}

D. B. Considine,${ }^{1,2}$ R. S. Stolarski, ${ }^{2}$ S. M. Hollandsworth, ${ }^{2,3}$ C. H. Jackman, ${ }^{2}$, and E. L. Fleming, ${ }^{2,3}$

Received ; accepted

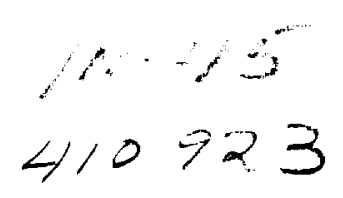

Revised version: September 16, 1998

Short title: A MONTE CARLO UNCERTAINTY ANALYSIS

\footnotetext{
${ }^{1}$ Joint Center For Earth System Science, University of Maryland, College Park, Maryland

${ }^{2}$ NASA Goddard Space Flight Center, Greenbelt, Maryland

${ }^{3}$ Space Applications Corporation, Vienna, Virginia
} 
Abstract. We use Monte Carlo analysis to estimate the uncertainty in predictions of total $\mathrm{O}_{3}$ trends between 1979 and 1995 made by the Goddard Space Flight Center (GSFC) two-dimensional (2D) model of stratospheric photochemistry and dynamics. The uncertainty is caused by gas-phase chemical reaction rates, photolysis coefficients, and heterogeneous reaction parameters which are model inputs. The uncertainty represents a lower bound to the total model uncertainty assuming the input parameter uncertainties are characterized correctly. Each of the Monte Carlo runs was initialized in 1970 and integrated for 26 model years through the end of 1995 . This was repeated 419 times using input parameter sets generated by Latin Hypercube Sampling. The standard deviation $(\sigma)$ of the Monte Carlo ensemble of total $\mathrm{O}_{3}$ trend predictions is used to quantify the model uncertainty. The $34 \%$ difference between the model trend in globally and annually averaged total $\mathrm{O}_{3}$ using nominal inputs and atmospheric trends calculated from Nimbus 7 and Meteor 3 total ozone mapping spectrometer (TOMS) version 7 data is less than the $46 \%$ calculated $1 \sigma$ model uncertainty, so there is no significant difference between the modeled and observed trends. In the northern hemisphere midlatitude spring the modeled and observed total $\mathrm{O}_{3}$ trends differ by more than $1 \sigma$ but less than $2 \sigma$, which we refer to as marginal significance. We perform a multiple linear regression analysis of the runs which suggests that only a few of the model reactions contribute significantly to the variance in the model predictions. The lack of significance in these comparisons suggests that they are of questionable use as guides for continuing model development. Large model/measurement differences which are many multiples of the input parameter uncertainty are seen in the meridional gradients of the trend and the peak-to-peak variations in the trends over an annual cycle. These discrepancies unambiguously indicate model formulation problems and provide a measure of model performance which can be used in attempts to improve such models. 


\section{Introduction}

Two dimensional (2D) models of stratospheric photochemistry and dynamics are used to study the changes that have occurred in column $\mathrm{O}_{3}$ levels over the past two decades and the factors responsible for those changes. The models are valuable for these studies because they are simple enough to be run for many years, but still describe the seasonal, meridional and vertical structure of the atmosphere.

Comparison of $2 \mathrm{D}$ model predicted total $\mathrm{O}_{3}$ changes with observations tests the adequacy of our understanding of the processes that have modified atmospheric $\mathrm{O}_{3}$ concentrations recently. Model/observation discrepancies are often taken as an indication that the model is incorrect and some important process is missing from the model formulation and our understanding. For instance, Solomon et al. [1996] noted that the agreement between the total $\mathrm{O}_{3}$ time series calculated from total ozone mapping spectrometer (TOMS) data and a 2D model was significantly improved by adding to the model a background sulfate aerosol layer which reproduced observed variations of the aerosol layer over the TOMS observing period. Jackman et al. [1996] included a parameterization of solar ultraviolet flux variations in addition to a realistically varying background sulfate aerosol and also found better agreement between the model and observations.

This "standard" method of utilizing 2D models to interpret observations has proved fruitful, but is limited because uncertainties in the values of model input parameters such as chemical reaction rates result in uncertain model output. If this uncertainty is large compared to a model/measurement discrepancy, then no significance can be attributed to the difference as it might easily be due to an input parameter error rather than a problem with the model formulation.

The propagation of input parameter uncertainties through atmospheric photochemistry and dynamics models is time-consuming but straightforward. The most common method to date is the Monte Carlo technique [Stolarski et al., 1978; 
Stolarski and Douglass, 1986; Douglass and Stolarski, 1987; Thompson and Stewart, 1991; Gao et al, 1996; Stewart and Thompson, 1997; Chen et al., 1997; Fish and Burton, 1997]. There has not been a great deal of work in this area, perhaps because it is generally felt that many important processes such as those controlling atmospheric transport are so crudely parameterized that input parameter uncertainties are likely to be small in comparison. Although this may be true, the goal of this paper is to quantitatively assess the uncertainty in $2 \mathrm{D}$ model predictions of $\mathrm{O}_{3}$ trends and to use this information to interpret comparisons between the model predictions and TOMS observations of trends in total $\mathrm{O}_{3}$. If a model/measurement discrepancy is rendered insignificant by known uncertainties in the input parameters, additional unquantified sources of uncertainty will not affect this result.

In this paper we use a Monte Carlo technique to evaluate the uncertainty in the $\mathrm{O}_{3}$ trend predictions of the GSFC 2D model. We consider the effects of uncertainties in chemical reaction rates, photolysis coefficients, and heterogeneous reaction rates. The model includes a parameterization of the solar cycle variation and a realistic variation of the sulfate aerosol surface area density between 1979 and 1995. In Section 2, we briefly describe the version of the GSFC 2D model used in these studies. In Section 3 , we discuss the Monte Carlo method and details of the runs analyzed in this paper. In Section 4, we present the results of the Monte Carlo uncertainty analysis. We summarize our results and draw some conclusions in Section 5.

\section{Model Description}

The Goddard Space Flight Center 2D model has been described fairly completely in numerous previous publications [e.g., Jackman et al., 1996, and references therein]. We briefly summarize its features here.

The model has a 10 degree latitudinal resolution, with the midpoints of the 18 latitude bands located at $-85^{\circ}, \ldots,+85^{\circ}$. The vertical coordinate is log-pressure with 
a resolution of about 2 kilometers. The model uses the residual circulation formulation described in Fleming et al. [1995]. Constituents are advected using the second-order moment scheme of Prather, [1986]. Note that the Jackman et al. [1996] study uses a somewhat different residual circulation formulation and a piecewise-parabolic advection scheme instead of second-order moments. These differences do not affect the conclusions of this study.

The model contains a fairly complete description of stratospheric chemical processes. It calculates the concentrations of 62 species. Of these, 28 are transported, and the remainder are calculated using photochemical equilibrium assumptions. Family approximations are used for $\mathrm{O}_{x}, \mathrm{NO}_{x}, \mathrm{ClO}_{x}$, and $\mathrm{Br}_{x}$ species. There are 106 gas phase chemical reactions in the model chemical scheme. The reaction rates are calculated from values specified in DeMore et al., [1994].

Heterogeneous reactions occur on a background sulfate aerosol layer. The sulfate aerosol surface area density distribution used to calculate the reaction rates is based on satellite extinction measurements made between 1979 and 1995 as described in Jackman et al. [1996]. The distribution represents the temporal variation of the zonal mean atmospheric sulfate aerosol layer in response to the various volcanic eruptions which have occurred since 1979. Heterogeneous reactions on Type 1 (nitric acid trihydrate) and Type 2 (water ice) polar stratospheric clouds (PSCs) are also included. The PSC surface area densities are calculated as in Considine et al. [1994]. All of the heterogeneous reactions included in the model are included in the Monte Carlo input parameter set described in Section 3 below. They are listed in Table A3 of the appendix.

There are 45 photolytic decomposition reactions included in the model. The photolysis coefficients are specified from a photolytic source term look-up table generated with the Anderson radiation code described in Anderson and Lloyd, [1990]. Cross sections are taken from DeMore et al., [1994]. The model also includes a parameterization of solar cycle variations in the solar UV flux, again as described in 
Jackman et al. [1996].

\section{Monte Carlo Methodology}

In a Monte Carlo analysis of the uncertainty in a particular model output, the model is run many times using a different set of input parameter values in each run. Each set is a combination of possibly correct input parameter values which are chosen on the basis of the specified uncertainty in each of the input parameters. Each input parameter value set results in different model output. The ensemble of model output values produced by the Monte Carlo runs is then used to characterize the output uncertainty resulting from uncertainties in the input parameters.

\section{Parameters}

Table A1 of the appendix lists the 93 chemical reactions whose uncertainties are propagated through the model in this study. Since the model includes 106 gas phase reactions in all, 13 reactions are not included as Monte Carlo parameters. These reactions are only important in the mesosphere so their neglect has no bearing on the study of uncertainty in total $\mathrm{O}_{3}$ predictions.

To understand how values used in the Monte Carlo runs are chosen for a particular reaction, consider a bimolecular reaction with the Arrhenius form,

$$
k(T)=A \exp \left(\frac{-E}{R}\left(\frac{1}{T}\right)\right),
$$

where $k(T)$ is the reaction rate at temperature $T, \mathrm{~A}$ is a constant, and $E / R$ is the activation energy in Kelvin. To make the discussion below easier to follow, note that this can be rewritten in terms of the reaction rate at $298 \mathrm{~K}, k_{298}$ :

$$
k(T)=k_{298} \exp \left(\frac{E}{R}\left(\frac{1}{298}-\frac{1}{T}\right)\right) .
$$


Both $k_{298}$ and $E / R$ are measured quantities and therefore are uncertain. In a Monte Carlo study, these uncertainties are represented with probability distributions which are then sampled in some way to obtain the set of values used in the Monte Carlo runs.

DeMore et al. [1994] provides an estimate of the uncertainty of $k_{298}$ and $E / R$, denoted $f_{298}$, and $\Delta E / R$, respectively. The publication also provides an equation for determining the uncertainty in the reaction at any temperature $T$,

$$
f(T)=f_{298} \exp \left|\frac{\Delta E}{R}\left(\frac{1}{T}-\frac{1}{298}\right)\right| .
$$

This expression cannot be used directly in a Monte Carlo study because it implies a different probability distribution characterizing the reaction uncertainty at each temperature. Sampling multiple probability distributions to obtain rates for a single reaction would destroy the Arrhenius form of the reaction rate.

In this paper we assume that the uncertainty in $k_{298}$ is described by a lognormal probability distribution and the uncertainty in $E / R$ is described by a normal distribution. A lognormal distribution is chosen for $k_{298}$ to exclude choosing negative values for this quantity, which would be physically unrealistic. No such constraint exists for $E / R$, so we characterize its uncertainty using a normal distribution with mean $E^{o} / R$ and standard deviation $\Delta E / R$ taken from DeMore et al. [1994].

The upper uncertainty bound for $k_{298}$ is specified in DeMore et al. [1994] by $k_{298}^{+}=k_{298}^{o} f_{298}$, where $k_{298}^{o}$ is the nominal value of the rate. Taking the logarithm of this relationship results in,

$$
\ln \left(k_{298}^{+}\right)=\ln \left(k_{298}^{o}\right)+\ln \left(f_{298}\right) .
$$

Since the upper uncertainty bound of a quantity is typically specified as one standard deviation above its mean value, this form suggests that we can describe the uncertainty in the logarithm of $k_{298}$ by a normal distribution with a mean of $\ln \left(k_{298}^{o}\right)$ 
and standard deviation $\ln \left(f_{298}\right)$. With this choice the uncertainty in $k_{298}$ is described by the lognormal distribution:

$$
P\left(k_{298}\right)=\frac{1}{\sqrt{(2 \pi)\left(k_{298} \ln \left(f_{298}\right)\right)}} \exp \left(\frac{-\ln ^{2}\left(\frac{k_{298}}{k_{298}^{o}}\right)}{2 \ln ^{2}\left(f_{298}\right)}\right) .
$$

To choose a rate for a bimolecular reaction in a Monte Carlo run, a value for $k_{298}$ is chosen by sampling Equation 5 and a value for $E / R$ is chosen by sampling the normal distribution describing its uncertainty. The rate of the reaction for that Monte Carlo run is then constructed from Equation 2. This method preserves the Arhennius form of the bimolecular reaction rates, as desired.

It should be noted that DeMore et al. [1994] does not provide a specific definition of the uncertainty bounds listed in the document. The publication instead states that the uncertainties are subjective and are not based on a rigorous statistical analysis of the available measurements for each rate. The interpretation of these limits we have adopted in this paper is therefore our own. While reasonable, it is not unique. For instance, Stewart et al. [1996] made the identification $f_{298}=1+s / m$, where $s$ and $m$ are the mean and standard deviation of the lognormal distribution characterizing the uncertainty in $k_{298}$. With this reasonable assumption, the standard deviation of $\ln \left(k_{298}\right)$ is not $\ln \left(f_{298}\right)$ as we assume but $\left(\ln \left(1+\left(f_{298}-1\right)^{2}\right)\right)^{(1 / 2)}$. This function increases slightly faster than $\ln \left(f_{298}\right)$ as $f_{298}$ increases, but not significantly so.

Termolecular reactions are treated similarly to the bimolecular case. DeMore et al. [1994] provides the functional form for a termolecular reaction in the low-pressure limit,

$$
k_{o}(T)=k_{o}^{300}[M]\left(\frac{T}{300}\right)^{-n},
$$

where $[M]$ is the number density of air, and $k_{o}^{300}[M]$ is the effective bimolecular rate of the reaction at 300 Kelvin in the low pressure limit. DeMore et al. [1994] also provide uncertainty estimates $\Delta k_{o}^{300}$ and $\Delta n$ for $k_{o}^{300}$ and $n$, respectively. We generate 
a lognormal distribution from $k_{o}^{300}$ and $\Delta k_{o}^{300}$ from which to pick values for the Monte Carlo runs and a normal distribution from $n$ and $\Delta n$. For simplicity, we have ignored the uncertainty of the termolecular reactions in the high pressure limit. Thus, the uncertainty distributions generated for the termolecular reactions underestimate the uncertainty in these reactions implied by the DeMore et al. [1994] values.

Table 2 of the appendix lists the 45 photolytic reactions whose uncertainties are propagated through the model in this study. The uncertainty distributions for 27 of the reactions were generated from the cross section uncertainty estimates listed in Table 5 of DeMore et al., [1994]. For the remaining reactions, an uncertainty of $f_{\sigma}=1.2$ was arbitrarily chosen. The cross-section uncertainties were applied at all wavelengths. The lognormal probability distribution characterizing the cross section uncertainty was generated similarly to the lognormal distribution characterizing $k_{298}$ discussed above. We assumed that the uncertainty in the logarithm of the cross section was characterized by a mean value $\ln \left(\sigma^{\circ}(\lambda)\right)$ where $\sigma^{o}$ is the nominal cross section value and $\lambda$ is the wavelength, and standard deviation $\ln \left(f_{\sigma}\right)$. We also assumed that the solar flux was uncertain by a factor $f_{s f}=1.1$, and varied its value accordingly in each Monte Carlo run.

Table 3 of the appendix lists the heterogeneous reaction parameters whose uncertainties are propagated through the model in this study. In addition to the surface reaction probabilities we also consider the size distributions of the Type 1 and Type 2 PSCs to be uncertain and the supersaturation required before the PSCs form. The uncertainties listed in Table 3 of the appendix were mostly taken from Table 59 of DeMore et al. [1994]. However, Table 59 did not provide uncertainty estimates for several of the reaction parameters. For these cases we chose an uncertainty based on a reading of the DeMore et al. [1994] table notes, personal communication with laboratory experimentalists [D. Hanson, personal communication, 1996], or primary laboratory measurement sources. These cases are indicated in footnotes to Table 3. 
Note that the conclusions of this paper are valid only to the extent that the characterization of the input parameter uncertainties described above is reasonable. If this is not the case, then the output uncertainty determined from the Monte Carlo runs will not reflect the actual uncertainty in the model results.

\section{Latin Hypercube Sampling}

Consider the uncertainty propagation of a single input parameter. A set of $\mathrm{N}$ values for the parameter are chosen and the model is run $\mathrm{N}$ times, once for each value. The variance in the model output of interest for the $\mathrm{N}$-run set characterizes its uncertainty due to the input parameter. To be valid, the set of $\mathrm{N}$ input parameter values used in the runs must correctly represent the uncertainty of the input parameter. If a model run requires significant computer time, then $\mathrm{N}$ must be made as small as possible in order for the study to be practical. However, it must still be large enough for the input parameter uncertainty to be well-sampled. It is therefore important to find an efficient method for selecting the input parameter values.

Consider two different techniques. The first is to randomly pick $\mathrm{N}$ input parameter values such that the probability of obtaining a particular value is equivalent to the probability that it is the true value of the parameter. The second method is to divide the input parameter range into $\mathrm{N}$ equal probability segments and take one input parameter value from each segment. The first method is known as Random Sampling (RS) and the second, when generalized to multiple input parameters, is known as Latin Hypercube Sampling (LHS). [e.g., McKay et al., 1979]. It has been found that the number of model runs necessary to obtain a good characterization of the uncertainty in an output parameter can be significantly smaller when LHS is used to choose the input parameter sets. This is because the LHS technique ensures that each input parameter is sampled over its entire range with the appropriate probability distribution in fewer runs than is necessary for random sampling. While LHS has not been proved to be better than RS 
in general, we chose this method on the basis of its demonstrated superiority in McKay et al. [1979]. We show below that the error in our application is slightly smaller than would be expected from a RS approach.

To use Latin Hypercube Sampling with $\mathrm{M}$ input parameter values and $\mathrm{N}$ runs, the range of each of the $M$ input parameters is first broken into $N$ equal probability segments. Then, one input parameter value is chosen for each segment. The result is a set of $M$ lists of values, (one for each parameter) each $N$ values long. An input parameter set for a Monte Carlo run is obtained by picking one value at random from each of the lists and then striking that value from the list so it will not be used again. Picking the values at random minimizes correlations between different input parameters. The process is repeated until $\mathrm{N}$ input parameter sets are generated.

\section{Run Specifics}

In our Latin Hypercube Sampling methodology we used a value of $N=50$. That is, for each of the 158 parameters we considered, we divided the uncertainty range into 50 equal probability segments. We then constructed 50 input parameter sets by picking a value at random from each of the 50-value lists and then striking the value so it could not be picked again. We repeated this process 9 times to obtain a total of 450 input parameter sets. This "replicated LHS" procedure [Iman and Conover, 1980] was adopted to allow us to evaluate the error in our predictions of model uncertainty, as explained below. Of the 450 runs we attempted, 419 completed successfully and 31 runs failed. The largest number of failed model runs for any 50 run replication was 6 . We did not attempt to rerun the failures with a modified code because we felt a less than $10 \%$ failure rate would have a minimal impact on our results and we wanted to ensure that the model formulation was the same in all of the runs. Each run was initialized in 1970 using the same initial conditions and run for 26 years, through the end of 1995.

Each run used a different input parameter set. Since the model adjusts to changes 
in input parameters within about 5 years, the study period after 1979 should not be affected by the model initialization. During the course of each 26 year run, source gas boundary conditions at the ground were time-stepped as described in Jackman et al. [1996]. Increases in chlorofluorocarbon emissions result in an increased stratospheric chlorine loading, contributing to the changes in $\mathrm{O}_{3}$ concentrations which are the subject of this paper.

From 1970-1979, the sulfate aerosol distribution was set to 1979 values for the appropriate month. From 1979 to 1995 the aerosol distribution was specified from the sulfate aerosol time series mentioned above. Also as mentioned above, a parameterization of the 11-year variation in the solar ultraviolet flux was also included in each run.

It is important to determine whether or not the number of Monte Carlo calculations made for this study is adequate. Imagine a Monte Carlo study with a very large number of runs. Each run gives a prediction for the model output of interest, which for example might be the percent change in globally and annually averaged total $\mathrm{O}_{3}$ between 1979 and 1992. As the number of runs becomes infinitely large, a limiting distribution for the model output with a mean value $\mu$ and a standard deviation $\sigma$ will be formed. Each model run produces a single sample of this limiting distribution. The $\sigma$ characterizes the uncertainty in the model output and is the quantity we attempt to estimate from a finite number of Monte Carlo runs.

In the case where the model input variables are chosen at random, each Monte Carlo run will be a random sample of the model output distribution. If $\mathrm{N}$ Monte Carlo runs are made a mean $\mu_{\mathrm{N}}$ and standard deviation $\sigma_{\mathrm{N}}$ can be calculated to estimate $\mu$ and $\sigma$. The standard error of these estimates is simply $\sigma / \sqrt{(\mathrm{N})}$. This suggests that with $\mathrm{N}=419$, the $\mu_{\mathrm{N}}$ and $\sigma_{\mathrm{N}}$ from a Random Sampling Monte Carlo calculation will be within about $5 \%$ of $\mu$ and $\sigma$. If LHS provides no benefit over Random Sampling then this is typical of the error in our uncertainty estimates.

The replicated LHS technique allows us to quantify the error in our predictions of $\sigma$ 
because we have 9 independent 50-run estimates of $\sigma$. The best estimate of $\sigma$ will be the average of the $9 \sigma_{\mathrm{N}}$ and the error will be given by the standard error of $\overline{\sigma_{N}}$. Consider for example the change in globally and annually averaged total $\mathrm{O}_{3}$ between 1979 and 1992. The nominal value for this model output is $-5.75 \%$. The average $\overline{\sigma_{N}}=2.66 \%$, with a standard error of $0.11 \%$. Therefore the error in our estimate of $\sigma$ is about $4.1 \%$, which is consistent with the error we would expect from a Random Sampling Monte Carlo approach and is sufficient for the purposes of this paper.

\section{Results}

\section{Total Ozone Trends}

Figure 1 compares the time series of the percent change in model annually averaged global total $\mathrm{O}_{3}$ since 1979 with observations made by the TOMS instrument. The model result using nominal input values is the solid line, while the TOMS observations are shown by the crosses. (Note that the nominal case corresponds to the median rather than the mean of the Monte Carlo runs.) The dashed lines above and below the model nominal case indicate plus and minus one standard deviation from the nominal values. The dotted lines on the plot show the high and low extrema of the Monte Carlo cases. Figure 1 shows that the agreement between the TOMS values and the nominal case is very good. The agreement is significantly better than would occur if solar cycle and sulfate aerosol variability were not included in the calculation, as shown in Jackman et al. [1996]. There is some disagreement between the model and observations due to year-to-year variability in the observations which does not occur in the model. Neither interannual dynamical variability nor the quasibiennial oscillation are included in the model formulation, which could account for some of the discrepancy.

The uncertainty in the model time series resulting from uncertain input parameters is substantial. For instance, the percent change in global total $\mathrm{O}_{3}$ between 1979 and 
1993 (the year of the maximum percent change from 1979) is about $6.5 \% \pm 2.5 \%(1 \sigma)$, indicating that the nominal model trend and the actual model trend (the trend the model would calculate if it were supplied a correct set of input parameter values) differ in relative terms by at most $40 \%$ with a likelihood of about 2 in 3 . Figure 1 also shows that the typical model/observation discrepancy is significantly smaller than the $1 \sigma$ error in the model time series. The relatively large model uncertainty indicates that these differences could easily be due to errors in the input reaction rates, and it can thus be argued that the differences between the TOMS data and the nominal model time series seen in Figure 1 are insignificant. This is essentially equivalent to the statement that the good agreement between the nominal model time series and the TOMS time series could be fortuitous - it might easily be that the model/measurement discrepancy would increase if the model were given the correct set of input parameter values as input.

As mentioned above the TOMS time series is influenced by interannual dynamical variations which do not occur in the model. This complicates the comparison of the observed and modeled changes in total $\mathrm{O}_{3}$ resulting from the buildup of chlorine in the stratosphere. In order to compare more directly the observed and calculated trend in $\mathrm{O}_{3}$ resulting from chlorine increases we have fit the total $\mathrm{O}_{3}$ time series from each of the Monte Carlo runs to a function similar to that used in the standard trend analysis of TOMS total $\mathrm{O}_{3}$ data using the same regression technique [McPeters et al., 1996]. We can then directly compare the model trend in $\mathrm{O}_{3}$ with the TOMS trend. Figure 2 compares the globally and annually averaged total $\mathrm{O}_{3}$ trend from the Monte Carlo runs with the trends calculated from the TOMS data. The histogram in the figure shows the distribution of the globally averaged model $\mathrm{O}_{3}$ trend produced by the 419 Monte Carlo runs. The histogram shows the probability that a Monte Carlo run produces a trend of a certain magnitude, resolved to a bin size of 0.4 percent per decade. The solid vertical line in the figure marks the nominal case trend of -3.02 percent/decade, and the dashed vertical lines show the $\pm 1 \sigma$ variation of 1.38 percent per decade around the nominal 
result. The dashed-dot vertical line shows the TOMS result of -2.26 percent per decade. The plot shows that the nominal model case is about $34 \%$ larger than the TOMS trend and that the two lie within the $1 \sigma$ uncertainty in the model result. This demonstrates more convincingly than the time series comparison above that the difference between the model and the TOMS trend is not significant. Errors in the nominal input parameter set could relatively easily be hiding better - or worse - model/measurement discrepancies.

Figure 3 shows the time series of annually averaged total $\mathrm{O}_{3}$ at 45 degrees north and south, again in terms of the percent change since 1979. The same plotting symbols are used here as in Figure 1. We have also included a 2-year running average of the TOMS data on the plot to smooth out the interannual and biannual variability and focus on the decadal time scales. This comparison tests the model more stringently than the globally averaged total $\mathrm{O}_{3}$ comparison shown in Figure 1 due to the larger influence of transport processes on column $\mathrm{O}_{3}$ at higher latitudes. Again we see very good agreement between the model nominal case and the TOMS observations. The discrepancies due to one-and two year interannual variations are larger in these plots than in the globally averaged case, but overall the model/measurement agreement is good enough to be considered fortuitous given the uncertainty in the model time series from the Monte Carlo runs.

To focus on the annually averaged $\mathrm{O}_{3}$ trend as a function of latitude we compare in Figure 4 the TOMS and model annually averaged total $\mathrm{O}_{3}$ trends as a function of latitude obtained using the regression model described above. As before the solid line represents the nominal case, the dashed lines show the $\pm 1 \sigma$ variation from the nominal case, and the crosses represent the TOMS data. Considering the model uncertainty in the tropics there is a statistically significant difference (at the $1 \sigma$ level) between the nominal trend of about 2 percent/decade and the TOMS values. However, the TOMS-calculated trends are also uncertain and it is possible that errors in both the model calculations and the TOMS data produce the discrepancy between the model nominal result and the TOMS trend. 
In the northern hemisphere midlatitudes Figure 4 shows that the model nominal annually averaged $\mathrm{O}_{3}$ trend and the TOMS-derived trend agree very well. However, the figure also shows that the uncertainty in the model result at these latitudes is large. For instance, at $55^{\circ} \mathrm{N}$ the model annually averaged $\mathrm{O}_{3}$ trend is $3.8 \pm 1.8$ percent/decade, an uncertainty of about $47 \%$. Because of this large uncertainty, the good agreement between the model and the observations is meaningless. It could easily be that errors in one the nominal input parameters are fortuitously countering a model formulation error which would be apparent if the correct input parameter values were used.

An obvious difference between the model and TOMS annually averaged total $\mathrm{O}_{3}$ trends shown in Figure 4 is the meridional gradient of the trend, which is significantly larger in the TOMS observations than in the model nominal case. The difference between the model and the observations can be examined more closely by calculating the meridional gradients in each of the Monte Carlo runs and comparing the variability in the gradient with the difference between the model and TOMS gradients. Figure 5 shows this comparison. The model meridional gradient of the annually averaged total $\mathrm{O}_{3}$ trend (percent per decade per degree latitude) is plotted with its $\pm 1 \sigma$ variability and is compared to the gradients in the TOMS annually averaged trends. The largest disagreements between the model nominal case and the TOMS results occur in the northern hemisphere at $35^{\circ}$ and in the southern hemisphere at $-55^{\circ}$. Both the northern and southern hemisphere model/measurement discrepancies are about 4-5 times the $1 \sigma$ uncertainty in the model gradient. These discrepancies are so large that it is unlikely that errors in the nominal input parameter set could be responsible for the large model/observation discrepancy. The weak model meridional gradients seen in the model are therefore likely to be due instead to errors in the model transport formulation.

Two-dimensional models have well-known problems in correctly capturing the characteristics of meridional transport in the atmosphere. These models often overestimate the amount of mixing between the tropics and midlatitudes, and between 
the midlatitudes and the polar vortex during winter [Bacmeister et al., 1995; Fahey et al., 1996]. It is thus not surprising that such a model would poorly represent the meridional gradients in the $\mathrm{O}_{3}$ trends. The model/measurement discrepancy seen in Figure 5 illustrates how a well-known model transport problem is revealed in this uncertainty analysis. Similar sorts of discrepancies may point to other less understood model formulation problems.

\section{Seasonal Total Ozone Trends}

Total $\mathrm{O}_{3}$ trends vary significantly over the course of the year and it is important to understand the factors contributing to this variation. Figure $6 \mathrm{a}$ shows the seasonal and meridional variation of Earth's total $\mathrm{O}_{3}$ as calculated from version 7 TOMS data from instruments on the Nimbus 7 and Meteor 3 satellites between November, 1978 and October, 1994. Conclusions concerning a model's ability to capture the trends in total $\mathrm{O}_{3}$ are typically drawn from such a plot. Figure $6 \mathrm{~b}$ shows the corresponding result from the the GSFC 2D model for the nominal input parameter set. Note that this differs slightly from that presented in Jackman et al. [1996] due to a somewhat different transport formulation in the two simulations.

Figure $6 \mathrm{c}$ shows the $1 \sigma$ uncertainty of the model calculation. This figure can be used to determine the significance of the discrepancies between the TOMS and model total $\mathrm{O}_{3}$ trends shown in Figures $6 \mathrm{a}$ and $6 \mathrm{~b}$, respectively. Figure $6 \mathrm{c}$ shows that the smallest uncertainties occur in the tropics, while the largest occur in the late spring/early summer in both the northern and southern hemisphere. The maximum uncertainty occurs in the southern hemisphere high latitudes where the model calculates the largest trends in total $\mathrm{O}_{3}$. Note, however, that as a fraction of the model calculated trend, the southern hemisphere high latitude uncertainty is actually a minimum, with the trend uncertainty as low as $25 \%$ of the trend itself. The maximum relative uncertainty of about $70 \%$ occurs at southern high latitudes in mid-winter. Throughout most of the 
year and over most of the globe, however, the relative uncertainty in the model is trend is fairly uniform, varying between $35 \%$ and $50 \%$.

It is often noted that models significantly underestimate total $\mathrm{O}_{3}$ trends in the northern hemisphere midlatitudes in March [e.g., Solomon et al., 1996]. The Monte Carlo calculation allows us to determine whether there really is a significant difference between the model calculation and the observations, or whether the discrepancy might easily be due to an error in the nominal model input parameters. Figure 7 is a plot of the probability distribution of the Monte Carlo runs for the middle of March, at $45^{\circ} \mathrm{N}$. As before, the Monte Carlo runs are distributed into bins with a width of 0.4 percent per decade. The solid vertical line indicates the model nominal trend of -3.59 percent per decade. The dashed vertical lines indicate the $\pm 1 \sigma$ variation around the nominal case of 1.63 percent per decade. The dash-dot vertical line indicates the TOMS trend value of -6.42 percent per decade. The plot shows that the difference between the model nominal case and the TOMS trend is significant at the $1 \sigma$ level, but not at $2 \sigma$. It is thus possible, but not very likely, that the discrepancy between the model nominal case and the TOMS data results from an error in the nominal case input parameters. One might refer to the model/measurement discrepancy in this case as being marginally significant. It is important to remember however that the uncertainty calculated from these Monte Carlo calculations does not include variations in the model transport formulation as a source of model uncertainty and is a lower bound to the total uncertainty in the model calculation. It is possible that the combination of dynamical and input uncertainties would be large enough to render the differences between the model and the observed total $\mathrm{O}_{3}$ trends insignificant at this latitude and time of year.

One fairly obvious difference between the TOMS trends shown in Figure 6a and the model trends in $6 \mathrm{~b}$ is a much larger seasonal variation in the observed trend than the model calculated trend. We note that a weak seasonal trend variability is a common model problem [World Meteorological Organization (WMO), 1995]. To examine this 
more closely we plot in Figure 8 the seasonal amplitude of the total $\mathrm{O}_{3}$ trend as a function of latitude, where the amplitude is calculated as the difference between the maximum trend and the minimum trend at a particular latitude. The trend amplitude for the model nominal case is the solid line, the dashed lines show the $\pm 1 \sigma$ variation around the nominal case, and the crosses show the TOMS trend amplitudes. The figure shows that the model underestimates the trend amplitude at most latitudes, but is particularly far from the mark in the northern hemisphere midlatitudes. Figure 8 also shows that the trend amplitude does not vary much between the Monte Carlo runs, so the difference between the model nominal case and the TOMS seasonal trend amplitude is up to 8.75 times $\sigma$ at $45^{\circ}$. In contrast to the discrepancy between the measured and modeled global total $\mathrm{O}_{3}$ trend (Figure 2) or the March midlatitude total $\mathrm{O}_{3}$ trend (Figure 7), this is a clear case where it is extremely unlikely that the difference between the model and the TOMS result is caused by an input parameter error. Here, it is very clear that the model formulation is incorrect, and resources can confidently be directed toward a real as opposed to a possible model problem.

\section{Sources of Uncertainty}

The Monte Carlo methodology provides a good estimate of the uncertainty of model output given a good characterization of the uncertainty in the model input parameters. However, the technique does not directly calculate which of the input parameters contribute strongly to the model output uncertainty and which do not. In this section we attempt to determine indirectly which parameters have the largest influence on the model output uncertainty.

Two factors determine the importance of the uncertainty in an input parameter to the model output uncertainty: 1 . The sensitivity of the model output to changes in that parameter; and 2. The magnitude of the input parameter uncertainty. If the model output of interest is insensitive to the input parameter, it does not matter how 
uncertain the value of that parameter is. On the other hand, a very precisely and accurately measured input parameter may not contribute greatly to the model output uncertainty even if there is a large sensitivity.

A typical strategy for determining the contribution of the model input parameters to the model output uncertainty in a Monte Carlo study is to fit the model output to an analytic function of the input parameters using a regression technique [e.g., Gao et al., 1996; Stewart et al., 1996]. The standard fitting function assumes a linear relationship between each input parameter and the output of interest. Thus,

$$
y=a_{0}+a_{1} p_{1}+a_{2} p_{2}+\ldots+a_{m} p_{m}
$$

where $y$ is the model output of interest, $p_{1}, \ldots, p_{m}$ are the fitting parameters, and $a_{0}, \ldots, a_{m}$ are the coefficients obtained from the regression analysis characterizing the linear relationship between the input parameter and the model output. There is no guarantee that this method will work everywhere in the model domain and at all times. However, as shown below the fit is often reasonable.

If the fit is good, then standard error propagation suggests that the contribution of the variance of each input parameter to the variance in the output can be approximated by

$$
\sigma_{y}^{2} \approx\left(\frac{\partial y}{\partial k_{1}}\right)^{2} \sigma_{1}^{2}+\left(\frac{\partial y}{\partial k_{2}}\right)^{2} \sigma_{2}^{2}+\ldots
$$

Given Equation $5, \partial y / \partial k_{i}=a_{i}$. To obtain a normalized result we calculate the fractional contribution of the ith parameter to the variance using

$$
f_{i}=\frac{a_{i}^{2} \sigma_{i}^{2}}{\sum_{i} a_{i}^{2} \sigma_{i}^{2}}
$$

We first examine the sources of uncertainty in the northern hemisphere midlatitude spring column $\mathrm{O}_{3}$ trends. To do this we have fit the percent change in column $\mathrm{O}_{3}$ 
between 1980 and 1990 at $45^{\circ} \mathrm{N}$ in March using a linear function of the input parameters as in Equation 5. The change in column $\mathrm{O}_{3}$ is most highly correlated with the reactions evaluated at the $38.5 \mathrm{mbar}$ level. This is the pressure level with the largest $\mathrm{O}_{3}$ concentration changes and hence the largest contributor to the change in column $\mathrm{O}_{3}$. The multiple linear correlation coefficient for the fit is 0.91 , indicating that the fitting equation can explain $91 \%$ of the variance in the change in column $\mathrm{O}_{3}$ calculated in the Monte Carlo runs. The quality of the fit is shown in Figure 9, which compares the model calculated percent change in column $\mathrm{O}_{3}$ on the $\mathrm{x}$-axis with the prediction of the linear relation expressed by Equation 5 on the y-axis. The points are reasonably compactly arranged along the 1-to-1 line as is required of a good fit. There is a tendency for the linear fit to underestimate somewhat the cases with the largest reductions in total $\mathrm{O}_{3}$.

The regression results in two measures of a parameter's importance: First is the linear correlation coefficient specifying the degree to which each individual parameter correlates with the change in total $\mathrm{O}_{3}$. Second is the fractional contribution to the total variance of the change in total $\mathrm{O}_{3}$ calculated from the multiple linear regression fit, as in Equation 7. The parameters which are most highly correlated with the change in total $\mathrm{O}_{3}$ also tend to be the largest contributors to the variance. Only a few of the fitted parameters have either high correlation coefficients or large fractional contributions to the total variance. There is also a significant correlation between the two - if a parameter has a large correlation coefficient it tends also to be a strong contributor to the variance. This implies that only a few of the parameters control the response of model total $\mathrm{O}_{3}$ distributions to changes in chlorine loading.

Table 1 shows the 11 parameters which have an absolute linear correlation coefficient larger than 0.1 and a fractional contribution to the variance larger than $2 \%$. For a 419 run data set, the probability that a correlation coefficient exceeds $0.1,0.15$, and 0.2 simply by chance is about $4 \%, 0.2 \%$, and $0.004 \%$, respectively. Thus it is likely that a physical relationship exists between these parameters and the model column $\mathrm{O}_{3}$ change. 
The second column of Table 1 lists the correlation coefficents for the reactions and the third column lists the fractional contribution of each of the tabulated parameters to the total variance in column $\mathrm{O}_{3}$ in the linear regression fit.

Table 1 shows that about $68 \%$ of the variance in the column $\mathrm{O}_{3}$ change from multiple linear regression fit is produced by these 11 reactions. The table also illustrates the importance of the odd nitrogen family in controlling the response of model total $\mathrm{O}_{3}$ to chlorine perturbations. Parameter 1 is the primary producer of $\mathrm{NO}_{y}$ in the atmosphere; the more $\mathrm{NO}_{y}$, the more increases in $\mathrm{Cl}_{y}$ will be stored in the reservoir forms via reactions of $\mathrm{ClO}$ with the $\mathrm{NO}_{y}$ radicals $\mathrm{NO}$ and $\mathrm{NO}_{2}$. Parameter 10 would tend to reduce the amount of background $\mathrm{NO}_{y}$ and hence reduce the fraction of $\mathrm{Cl}_{y}$ in reservoir forms. Parameters 2,5 , and 7 convert reservior forms of $\mathrm{NO}_{y}$ to reactive forms which can tie up $\mathrm{Cl}_{y}$ in its reservoir forms. Parameter 8 is an essential step in the formation of $\mathrm{HNO}_{3}$, removing forms of $\mathrm{NO}_{y}$ which can react with $\mathrm{Cl}_{y}$ species.

Parameters 3 and 9 are reactions which directly control the partitioning $\mathrm{Cl}_{y}$. They both force the partitioning of $\mathrm{Cl}_{y}$ toward more active forms, resulting in negative correlation coefficients. Parameter 4 also has an understandable effect, reducing the amount of $\mathrm{OH}$ available to convert $\mathrm{HCl}$ to reactive chlorine and resulting in a positive correlation. Parameter 11 produces numerous changes which would be expected to reduce the $\mathrm{O}_{3}$ trend such as increasing the production of $\mathrm{HO}_{x}$ and $\mathrm{NO}_{y}$ and changing the partitioning of $\mathrm{Cl}_{y}$ in favor of reservior forms. It is not obvious which of these might dominate the others.

The parameters shown in Table 1 are those which are most strongly correlated with the changes in column $\mathrm{O}_{3}$ produced by increases in stratospheric $\mathrm{Cl}_{y}$ concentrations. It is interesting but not surprising to note that a different set of parameters are highly correlated with background $\mathrm{O}_{3}$ concentrations. A set of 9 of these parameters for $45^{\circ} \mathrm{N}$, in March at $38.5 \mathrm{mbar}$, are shown in Table 2. The listed parameters have linear correlation coefficients greater than 0.1 and contribute more than $1 \%$ to the variance 
in the multiple linear regression fit. The multiple linear correlation coefficient for this fit is 0.96 , which is better than for the fit to changes in column $\mathrm{O}_{3}$ amounts discussed above. By far the most highly correlated parameter is $\mathrm{O}_{2}$ photolysis, which is the primary $\mathrm{O}_{x}$ production mechanism. This parameter is itself responsible for almost $60 \%$ of the variance in background $\mathrm{O}_{3}$ concentrations, and together these 9 input parameters account for about $85 \%$ of the total variance in the $\mathrm{O}_{3}$ levels calculated from the multiple linear regression fit.

The fact that different input parameters control the background $\mathrm{O}_{3}$ concentrations and its response to $\mathrm{Cl}_{y}$ perturbations suggests that it is not possible to conclude from a model's good reproduction of observed $\mathrm{O}_{3}$ levels that its response to a perturbation will be reliable. This should be established instead from a model's ability to reproduce observed changes in $\mathrm{O}_{3}$.

Figure 6a shows that the largest model trends in column $\mathrm{O}_{3}$ occur in the southern hemisphere high latitude spring. The input parameters which apparently control the sensitivity of the model southern hemisphere high latitude region in spring are shown in Table 3. The multiple linear correlation coefficient here is about 0.81 , so the regression model is less able to account for the variance in the model calculated change in column $\mathrm{O}_{3}$ at this location than at midlatitudes. Also, the fraction of the total variance contributed by the 11 listed parameters is about $54 \%$, lower than for the midlatitude column $\mathrm{O}_{3}$ change discussed above.

Several of the important midlatitude northern hemisphere input parameters shown in Table 1 reappear in this table. However, the increased role of heterogeneous reactions and halogen chemistry is reflected in the appearance in the table of the Type $2 \mathrm{PSC}$ radius, the $\mathrm{ClO}+\mathrm{BrO}$ reactions, and the heterogeneous reaction $\mathrm{ClONO}_{2}+\mathrm{H}_{2} \mathrm{O} \rightarrow \mathrm{HOCl}+\mathrm{HNO}_{3}$ on ice. The rate of this reaction has a factor of 10 uncertainty associated with it according to DeMore et al., [1994], which might explain its appearance on this list over other ice-catalyzed reactions which have larger sticking 
coefficients.

\section{Summary and Conclusions}

We have presented a Monte Carlo estimate of the uncertainty in total $\mathrm{O}_{3}$ trend predictions made using the GSFC 2D model. This uncertainty results from uncertainties in input gas phase and heterogeneous reaction rates, and photolysis coefficients. We have used Latin Hypercube Sampling to reduce the number of runs necessary to obtain a good estimate of the uncertainty. Given this technique, the 419 runs completed for this study should result in an error of no more than a few percent.

The uncertainty in the model predictions of globally and annually averaged trends in total $\mathrm{O}_{3}$ are large enough such that the difference between the model predictions and the trends calculated from Nimbus 7 and Meteor 3 TOMS data are insignificant. We find a marginally significant difference between modeled and observed equatorial annually averaged total $\mathrm{O}_{3}$ trends which is insignificant when errors in the TOMS calculation are considered in addition to the model uncertainty. At mid to higher latitudes the differences between measured and observed annually averaged trends in column $\mathrm{O}_{3}$ are again insignificant. The difference between modeled and observed total $\mathrm{O}_{3}$ trends in March at $45^{\circ} \mathrm{N}$ is marginally significant when considering the uncertainty in the model calculation only. Assuming the input parameter uncertainty estimates to be true, it is possible that the differences between the model results and the observations

in these cases arise from errors in the input parameters and not from an incorrect model formulation. Thus it seems that efforts to increase the agreement between the model and the observations in these cases by changing the model formulation might be wasted without more precise and accurate specification of the model input parameters.

Good agreement between a model and the observations listed above might simply be due to fortuitously compensating errors in some input parameter and the model formulation, so grading the performance of a model using such observations should also 
be avoided until the differences between the model results and observations can be shown to be significant.

Clearly significant differences between the modeled and observed trends are seen in the meridional gradients of the annually averaged trends at midlatitudes and the seasonal trend amplitude at all latitudes. It is quite unlikely that these differences could be caused by errors in the input parameters so it is very likely that they are the result of an incorrect model formulation. Further model development efforts can be directed toward resolving these discrepancies.

The contribution of a particular input parameter uncertainty to the total model output uncertainty depends both on the magnitude of the input parameter uncertainty and the sensitivity of the model to that parameter. Direct information concerning the contribution of each input parameter is not available in a Monte Carlo analysis, but an approximation can be made by fitting the model output to a linear function of the input parameters and then determining the contribution of the variance in each input parameter to the total variance of the regression model fit. This technique reveals that only a few of the input parameters contribute much to the variance at any particular location. Reducing the uncertainty of those parameters would produce the largest decreases in model uncertainty. The regression analysis also shows that the parameters controlling the variance in background $\mathrm{O}_{3}$ concentrations are not the same as the ones producing variance in the model response to $\mathrm{Cl}_{y}$ increases.

We stress that the validity of these output uncertainty calculations depends on a correct evaluation of the input parameter uncertainties. If these are generally overestimated then the uncertainty in the model calculations will also be overestimated. There is some observational evidence to suggest that interpreting the DeMore et al. [1994] values as $1 \sigma$ uncertainties overestimates the actual uncertainties in the tabulated rates. Cohen et al. [1994] made this assumption when comparing observed $\mathrm{HO}_{x}$ partitioning from aircraft observations to the predictions of a simple analytical model, 
and found better model/measurement agreement than expected from the calculated uncertainties. In such a situation model/measurement discrepancies that indicate model problems might incorrectly be judged to be the insignificant consequence of input parameter errors. A more specific recommendation on how to interpret the DeMore et al. [1994] uncertainty estimates would be helpful in future uncertainty studies.

Acknowledgments. We would like to thank NASA's Atmospheric Chemistry, Modeling, and Analysis Program (ACMAP) for its support of this research. 


\section{References}

Anderson, D. E., Jr., and S. A. Lloyd, Polar twolight UV-visible radiation field: Perturbations due to multiple scattering, ozone depletion, stratospheric clouds, and surface albedo, $J$. Geophys. Res., 95, 7429-7434, 1990.

Bacmeister, J. T., M. R. Schoeberl, M. E. Summers, J. R. Rosenfield, and X. Zhu, Descent of long-lived trace gases in the winter polar vortex, J. Geophys. Res., 100, 11669-11684, 1995.

Chen, L., H. Rabitz, D. B. Considine, C. H. Jackman, and J. A. Shorter, Chemical reaction rate sensitivity and uncertainty in a two-dimensional middle atmospheric ozone model, J. Geophys. Res., 102, 16201-16214, 1997.

Considine, D. B., A. R. Douglass, and C. H. Jackman, Effects of a polar stratospheric cloud parameterization on ozone depletion due to stratospheric aircraft in a two-dimensional model, J. Geophys. Res., 99, 18879-18894, 1994.

DeMore, W. B., D. M. Golden, R. F. Hampson, C. J. Howard, C. E. Kolb, M. J. Kurylo, M. J. Molina, A. R. Ravishankara, and S. P. Sander, Chemical kinetics and photochemical data for use in stratospheric modeling, Evaluation number 11, JPL Publ., 94-26, 273 pp., 1994.

Douglass, A. R., and R. S. Stolarski, The use of atmospheric measurements to constrain model predictions of ozone change from chlorine perturbations, J. Geophys. Res., 92, $6662-6674,1987$.

Douglass, A. R., C. H. Jackman, and R. S. Stolarski, Comparison of model results transporting the odd nitrogen family with results transporting separate odd nitrogen species, $J$. Geophys. Res., 94, 9862-9872, 1989.

Fahey, D. W., et al., In situ observations of $\mathrm{NO}_{y}, \mathrm{O}_{3}$, and the $\mathrm{NO}_{y} / \mathrm{O}_{3}$ ratio in the lower stratosphere, Geophys. Res. Lett., 23, 1653-1656, 1996.

Fish, D. J., and M. R. Burton, The effect of uncertainties in kinetic and photochemical data on model predictions of stratospheric ozone depletion, J. Geophys. Res., 102, $25,537-25,542,1997$. 
Fleming, E. L., S. Chandra, C. H. Jackman, D. B. Considine, and A. R. Douglass, The middle atmospheric response to short and long term solar UV variations: Analysis of observations and 2D model results, J. Atmos. Terr. Phys.57 3333651995

Gao, D., W. R. Stockwell, and J. B. Milford, Global uncertainty analysis of a regional-scale gas-phase chemical mechanism, J. Geophys. Res., 101, 9107-9119, 1996.

Hanson, D. R., and A. R. Ravishankara, Heterogeneous chemistry of bromine species in sulfuric-acid under stratospheric conditions, Geophys. Res. Lett., 22, 385-388, 1995.

Iman and Conover, Small sample sensitivity analysis techniques for computer models, with an application to risk assessment," Comm. Stat. A, 9, 1749-1874, 1980.

Jackman, C. H., A. R. Douglass, R. B. Rood, R. D. McPeters, and P. E. Meade, Effect of solar proton events on the middle atmosphere during the past two solar cycles as computed using a two-dimensional model, J. Geophys. Res., 95, 7417-7428, 1990.

Jackman, C. H., E. L. Fleming, S. Chandra, D. B. Considine, and J. E. Rosenfield, Past, present, and future modeled ozone trends with comparisons to observed trends, $J$. Geophys. Res., 101, 28753-28767, 1996.

McKay, M. D., R. J. Beckmand, and W. J. Conover, A comparison of three methods for selecting values of input variables in the analysis of output from a computer code, Technometrics, 21, 239-245, 1979.

McPeters, R. D., S. M. Hollandsworth, L. E. Flynn, J. R. Herman, and C. J. Seftor, Long-term ozone trends derived from the 16-year combined Nimbus 7 Meteor 3 TOMS Version 7 record, Geophys. Res. Lett., 23, 3699-3702, 1996.

Prather, M. J., Numerical advection by conservation of second-order moments, J. Geophys. Res., 91, 6671-6681, 1986.

Solomon, S., R. W. Portmann, R. R. Garcia, L. W. Thomason, L. R. Poole, and M. P. McCormick, The role of aerosol variations in anthropogenic ozone depletion at northern midlatitudes, J. Geophys. Res., 101, 6713-6727, 1996.

Stewart, R. W., and A. M. Thompson, Kinetic data imprecisions in photochemical rate calculations: Means, medians and temperature dependence, J. Geophys. Res., 101, 20953-20964, 1997. 
Stolarski, R. S., D. M. Butler, and R. D. Rundel, Uncertainty propagation in a stratospheric model 2. Monte Carlo analysis of imprecisions due to reaction rates, J. Geophys. Res., $83,3074-3078,1978$.

Stolarski, R. S., and A. R. Douglass, Sensitivity of an atmospheric photochemistry model to chlorine perturbations including consideration of uncertainty propagation, J. Geophys. Res., 91, 7853-7864, 1986.

Thompson, A. M., and R. W. Stewart, Effect of chemical kinetics uncertainties on calculated constituents in a tropospheric photochemical model, J. Geophys. Res., 966, 13089-13108, 1991.

World Meteorological Organization (WMO), Scientific assessment of stratospheric ozone: 1994, Rep. 37, Global Ozone Res. and Monit. Proj., World Meteorol. Org., Geneva, 1995.

This manuscript was prepared with the AGU IATEX macros v3.0.

Figure 1. Percent change in the GSFC 2D model annually and globally $\left(65^{\circ} \mathrm{S}-65^{\circ} \mathrm{N}\right)$ averaged total $\mathrm{O}_{3}$ since 1979 compared with observations made by the TOMS instrument. The solid line is the model simulation using nominal rates, the dashed lines indicate the $\pm 1 \sigma$ variation calculated from the 419 model runs analyzed in this study, and the dotted lines indicate the high and low extreme cases. The crosses represent annually and globally averaged TOMS data. 
Figure 2. Globally and annually averaged total $\mathrm{O}_{3}$ trends from the Monte Carlo runs compared with trends derived from the TOMS data. Shown is a histogram of the Monte Carlo run results grouped into $0.4 \%$ decade bins. The histogram gives the probability that a Monte Carlo run resulted in a particular trend in globally and annually averaged total $\mathrm{O}_{3}$. The solid vertical line is the trend for the nominal case, the dashed lines show the $\pm 1 \sigma$ variation in the Monte Carlo runs, and the dashed-dotted line indicates the TOMS result.

Figure 3. Percent change since 1979 of annually averaged total $\mathrm{O}_{3}$ for the GSFC $2 \mathrm{D}$ model at $45^{\circ}$ North and South compared to TOMS observations. The solid, dashed, and dotted lines, as well as the crosses, are as in Figure 2. The long dashed line shows a 2 year running average of the TOMS data.

Figure 4. Latitude dependence of the annually averaged trend in total $\mathrm{O}_{3}$, in $\% /$ decade. The solid line shows the modal nominal case, the dashed lines indicate the $\pm 1 \sigma$ uncertainty in the result calculated from the Monte Carlo runs, and the crosses indicate the annually averaged trend in total $\mathrm{O}_{3}$ calculated from the TOMS data.

Figure 5. Meridional gradient in annually averaged trend in total $\mathrm{O}_{3}$ calculated by the GSFC 2D model, its uncertainty from the Monte Carlo runs, and comparison to TOMS observations. The solid line shows the nominal case gradient in the annually averaged total $\mathrm{O}_{3}$ trend, in $\% /$ decade/degree latitude. The dashed lines show the $\pm 1 \sigma$ variation in the gradient calculated using the Monte Carlo runs. The crosses show the trend gradients calculated using Nimbus 7 and Meteor 3 TOMS observations.

Figure 6. Meridional and seasonal dependence of the TOMS total $\mathrm{O}_{3}$ trends, and modelcalculated total $\mathrm{O}_{3}$ trends and trend uncertainty. a. TOMS trends calculated from version 7 Nimbus 7 and Meteor 3 TOMS data in \%/decade. b. The model trend using nominal values of the input parameters and the same statistical model as in the TOMS calculations, minus a QBO term. c. Monte Carlo estimate of the uncertainty in the model-calculated total $\mathrm{O}_{3}$ trend, in $\% /$ decade. 
Figure 7. Probability distribution of total $\mathrm{O}_{3}$ trend calculations for March at $45^{\circ} \mathrm{N}$ from the Monte Carlo runs compared to the observed trend. Shown is a histogram of 419 model calculations divided into $0.4 \% /$ decade bins and normalized to be expressed as a probability. The model result using nominal input parameter values is the solid vertical line. The dashed lines show the $\pm 1 \sigma$ values. The dot-dash line shows the total $\mathrm{O}_{3}$ trend calculated with TOMS data for March at $45^{\circ} \mathrm{N}$.

Figure 8. Seasonal total $\mathrm{O}_{3}$ trend amplitude as a function of latitude. The amplitude is defined as the difference between the maximum and the minimum trend in total $\mathrm{O}_{3}$ at a particular latitude. The nominal case, $\pm 1 \sigma$ variation, and TOMS values are indicated by the solid line, dashed lines, and crosses, respectively.

Figure 9. Comparison of model calculated 1980-1990 percent change in column $\mathrm{O}_{3}$ at $45^{\circ} \mathrm{N}$ in March with predicted changes from a multiple linear regression fit to the model values. The crosses show the values for each of the 419 Monte Carlo runs. 
Table 1. Regression analysis of March 1980-1990 percent change in column $\mathrm{O}_{3}$ at $45^{\circ}$ and pressure of 38.5 mbar. Analysis is based on 419 Monte Carlo runs fit to 158 input parameters.

\begin{tabular}{lcc}
\hline \multicolumn{1}{c}{ PARAMETER } & CORRELATION & FRACTION \\
\hline $\mathrm{N}_{2} \mathrm{O}+\mathrm{O}\left({ }^{1} \mathrm{D}\right) \rightarrow \mathrm{NO}+\mathrm{NO}$ & 0.350 & 15.19 \\
$\mathrm{HNO}_{3}+\mathrm{OH} \rightarrow \mathrm{NO}_{3}+\mathrm{H}_{2} \mathrm{O}$ & 0.295 & 12.06 \\
$\mathrm{HCl}+\mathrm{OH} \rightarrow \mathrm{Cl}+\mathrm{H}_{2} \mathrm{O}$ & -0.289 & 6.84 \\
$\mathrm{O}_{3}+\mathrm{OH} \rightarrow \mathrm{HO}_{2}+\mathrm{O}_{2}$ & 0.273 & 3.50 \\
$\mathrm{~N}_{2} \mathrm{O}_{5}+\mathrm{h} \nu \rightarrow \mathrm{NO}_{2}+\mathrm{NO}_{3}$ & 0.272 & 12.02 \\
$\mathrm{~N}_{2} \mathrm{O}_{5}+\mathrm{H} \mathrm{O}_{2} \rightarrow 2 \mathrm{HNO}_{3}(\mathrm{sulph})$ & -0.259 & 3.76 \\
$\mathrm{~N}_{2} \mathrm{O}_{5}+\mathrm{M} \rightarrow \mathrm{NO}_{2}+\mathrm{NO}_{3}+\mathrm{M}$ & 0.198 & 2.03 \\
$\mathrm{NO}_{2}+\mathrm{O}_{3} \rightarrow \mathrm{NO}_{3}+\mathrm{O}_{2}$ & -0.194 & 4.50 \\
$\mathrm{Cl}+\mathrm{O}_{3} \rightarrow \mathrm{ClO}+\mathrm{O}_{2}$ & -0.187 & 3.15 \\
$\mathrm{~N}_{2} \mathrm{O}+\mathrm{h} \nu \rightarrow \mathrm{N}_{2}+\mathrm{O}$ & -0.161 & 2.05 \\
$\mathrm{O}_{3}+\mathrm{h} \nu \rightarrow \mathrm{O}_{2}+\mathrm{O}\left({ }^{1} \mathrm{D}\right)$ & 0.108 & 2.79 \\
\hline
\end{tabular}


Table 2. Regression analysis of 419 Monte Carlo runs for $\mathrm{March}_{3}$ at $45^{\circ}$ and 38.5 mbar with colocated input parameters.

\begin{tabular}{lcc}
\hline \multicolumn{1}{c}{ PARAMETER } & CORRELATION & FRACTION \\
\hline $\mathrm{O}_{2}+\mathrm{h} \nu \rightarrow \mathrm{O}+\mathrm{O}$ & 0.723 & 59.86 \\
$\mathrm{O}+\mathrm{O}_{2}+\mathrm{M} \rightarrow \mathrm{O}_{3}+\mathrm{M}$ & 0.307 & 10.32 \\
$\mathrm{NO}+\mathrm{O}_{3} \rightarrow \mathrm{NO}_{2}+\mathrm{O}_{2}$ & -0.156 & 1.39 \\
$\mathrm{O}_{3}+\mathrm{h} \nu \rightarrow \mathrm{O}_{2}+\mathrm{O}$ & -0.141 & 3.82 \\
$\mathrm{OH}+\mathrm{O}_{3} \rightarrow \mathrm{HO}_{2}+\mathrm{O}_{2}$ & -0.120 & 1.46 \\
$\mathrm{NO}_{2}+\mathrm{O} \rightarrow \mathrm{NO}+\mathrm{O}_{2}$ & -0.119 & 2.18 \\
$\mathrm{HO}_{2}+\mathrm{O}_{3} \rightarrow \mathrm{OH}+2 \mathrm{O}_{2}$ & -0.115 & 3.67 \\
$\mathrm{O}_{3}+\mathrm{h} \nu \rightarrow \mathrm{O}_{2}+\mathrm{O}\left({ }^{1} \mathrm{D}\right)$ & -0.106 & 1.26 \\
$\mathrm{HCl}+\mathrm{OH} \rightarrow \mathrm{Cl}+\mathrm{H}_{2} \mathrm{O}$ & -0.105 & 1.16 \\
\hline
\end{tabular}


Table 3. Regression analysis of $\Delta$ column $\mathrm{O}_{3}$ between 1980 and 1990 in October at $75^{\circ} \mathrm{S}$. Analysis is based on 419 Monte Carlo runs fit to 158 input parameters evaluated in October at $75^{\circ} \mathrm{S}$ and 39 mbar.

\begin{tabular}{|c|c|c|}
\hline PARAMETER & CORRELATION & FRACTION \\
\hline $\mathrm{O}_{2}+\mathrm{h} \nu \rightarrow \mathrm{O}+\mathrm{O}$ & 0.314 & 10.47 \\
\hline Type 2 Aerosol Radius & 0.253 & 6.07 \\
\hline $\mathrm{BrO}+\mathrm{ClO} \rightarrow \mathrm{Br}+\mathrm{ClOO}$ & -0.177 & 3.61 \\
\hline $\mathrm{N}_{2} \mathrm{O}+\mathrm{O}\left({ }^{1} \mathrm{D}\right) \rightarrow \mathrm{NO}+\mathrm{NO}$ & 0.173 & 4.07 \\
\hline $\mathrm{HNO}_{3}+\mathrm{OH} \rightarrow \mathrm{NO}_{3}+\mathrm{H}_{2} \mathrm{O}$ & 0.171 & 6.87 \\
\hline $\mathrm{N}_{2} \mathrm{O}_{5}+\mathrm{H}_{2} \mathrm{O} \rightarrow 2 \mathrm{HNO}_{3}($ sulph $)$ & -0.156 & 2.21 \\
\hline $\mathrm{BrO}+\mathrm{ClO} \rightarrow \mathrm{Br}+\mathrm{OClO}$ & -0.146 & 5.78 \\
\hline $\mathrm{HCl}+\mathrm{OH} \rightarrow \mathrm{Cl}+\mathrm{H}_{2} \mathrm{O}$ & -0.141 & 4.57 \\
\hline $\mathrm{O}+\mathrm{O}_{2}+\mathrm{M} \rightarrow \mathrm{O}_{3}+\mathrm{M}$ & 0.126 & 3.41 \\
\hline $\mathrm{ClONO}_{2}+\mathrm{H}_{2} \mathrm{O} \rightarrow \mathrm{HNO}_{3}+\mathrm{HOCl}$ & -0.111 & 4.00 \\
\hline $\mathrm{CH}_{4}+\mathrm{Cl} \rightarrow \mathrm{CH}_{3}+\mathrm{HCl}$ & 0.100 & 2.98 \\
\hline
\end{tabular}


Table 3. Gas phase reactions varied in Monte Carlo runs

\begin{tabular}{|c|c|c|c|}
\hline Parameter & Name & $f_{298}$ or $\Delta k_{o}^{300}$ & $\Delta E / R$ or $\Delta n$ \\
\hline $\mathrm{R} 1$ & $\mathrm{O}+\mathrm{O}_{2}+\mathrm{M} \rightarrow \mathrm{O}_{3}+\mathrm{M}$ & $5 . \mathrm{e}-35$ & 0.5 \\
\hline $\mathrm{R} 2$ & $\mathrm{O}+\mathrm{O}_{3} \rightarrow 2 \mathrm{O}_{2}$ & 1.15 & 250 \\
\hline R3 & $\mathrm{H}+\mathrm{O}_{2}+\mathrm{M} \rightarrow \mathrm{HO}_{2}+\mathrm{M}$ & 5.e-33 & 0.5 \\
\hline R4 & $\mathrm{OH}+\mathrm{O}_{3} \rightarrow \mathrm{HO}_{2}+\mathrm{O}_{2}$ & 1.3 & 300 \\
\hline R5 & $\mathrm{HO}_{2}+\mathrm{O}_{3} \rightarrow \mathrm{OH}+2 \mathrm{O}_{2}$ & 1.3 & 500 \\
\hline $\mathrm{R} 6$ & $\mathrm{ClO}+\mathrm{HO}_{2} \rightarrow \mathrm{HOCl}+\mathrm{O}_{2}$ & 1.4 & 250 \\
\hline R7 & $\mathrm{Cl}+\mathrm{H}_{2} \mathrm{O}_{2} \rightarrow \mathrm{HCl}+\mathrm{HO}_{2}$ & 1.5 & 500 \\
\hline $\mathrm{R} 8$ & $\mathrm{O}\left({ }^{1} \mathrm{D}\right)+\mathrm{M} \rightarrow \mathrm{O}\left({ }^{3} \mathrm{P}\right)+\mathrm{M}$ & 1.2 & 100 \\
\hline $\mathrm{R} 9$ & $\mathrm{NO}+\mathrm{O}_{3} \rightarrow \mathrm{NO}_{2}+\mathrm{O}_{2}$ & 1.2 & 200 \\
\hline R10 & $\mathrm{NO}_{2}+\mathrm{O}_{3} \rightarrow \mathrm{NO}_{3}+\mathrm{O}_{2}$ & 1.15 & 150 \\
\hline R11 & $\mathrm{H}+\mathrm{O}_{3} \rightarrow \mathrm{OH}+\mathrm{O}_{2}$ & 1.25 & 200 \\
\hline $\mathrm{R} 12$ & $\mathrm{OH}+\mathrm{OH}+\mathrm{M} \rightarrow \mathrm{H}_{2} \mathrm{O}_{2}+\mathrm{M}$ & $3.0 \mathrm{e}-31$ & 2.0 \\
\hline $\mathrm{R} 13$ & $\mathrm{OH}+\mathrm{ClONO}_{2} \rightarrow \mathrm{HOCl}+\mathrm{NO}_{3}$ & 1.5 & 200 \\
\hline R14 & $\mathrm{CH}_{4}+\mathrm{OH} \rightarrow \mathrm{CH}_{3}+\mathrm{H}_{2} \mathrm{O}$ & 1.1 & 150 \\
\hline R15 & $\mathrm{CH}_{3} \mathrm{O}_{2}+\mathrm{NO} \rightarrow \mathrm{CH}_{3} \mathrm{O}+\mathrm{NO}_{2}$ & 1.5 & 180 \\
\hline R16 & $\mathrm{OH}+\mathrm{CH}_{3} \mathrm{Cl} \rightarrow \mathrm{H}_{2} \mathrm{O}+\mathrm{CH}_{2} \mathrm{Cl}$ & 1.2 & 250 \\
\hline R17 & $\mathrm{CH}_{3} \mathrm{O}+\mathrm{O}_{2} \rightarrow \mathrm{CH}_{2} \mathrm{O}+\mathrm{HO}_{2}$ & 1.5 & 300 \\
\hline $\mathrm{R} 18$ & $\mathrm{OH}+\mathrm{NO}_{2}+\mathrm{M} \rightarrow \mathrm{HNO}_{3}+\mathrm{M}$ & $3 e-31$ & 0.7 \\
\hline R19 & $\mathrm{HO}_{2}+\mathrm{HO}_{2} \rightarrow \mathrm{H}_{2} \mathrm{O}_{2}+\mathrm{O}_{2}$ & 1.3 & 200 \\
\hline $\mathrm{R} 20$ & $\mathrm{~N}+\mathrm{O}_{2} \rightarrow \mathrm{NO}+\mathrm{O}$ & 1.25 & 400 \\
\hline $\mathrm{R} 21$ & $\mathrm{CH}_{2} \mathrm{O}+\mathrm{O} \rightarrow \mathrm{HCO}+\mathrm{OH}$ & 1.25 & 250 \\
\hline $\mathrm{R} 22$ & $\mathrm{CH}_{3} \mathrm{O}_{2}+\mathrm{HO}_{2} \rightarrow \mathrm{CH}_{3} \mathrm{OOH}+\mathrm{O}_{2}$ & 2.0 & 400 \\
\hline $\mathrm{R} 23$ & $\mathrm{Cl}+\mathrm{H}_{2} \rightarrow \mathrm{HCl}+\mathrm{H}$ & 1.25 & 200 \\
\hline $\mathrm{R} 24$ & $\mathrm{Cl}+\mathrm{O}_{3} \rightarrow \mathrm{ClO}+\mathrm{O}_{2}$ & 1.15 & 100 \\
\hline $\mathrm{R} 25$ & $\mathrm{ClO}+\mathrm{O} \rightarrow \mathrm{Cl}+\mathrm{O}_{2}$ & 1.3 & 70 \\
\hline
\end{tabular}


Table 3. (continued)

\begin{tabular}{|c|c|c|c|}
\hline Parameter & Name & $f_{298}$ or $\Delta k_{o}^{300}$ & $\Delta E / R$ or $\Delta n$ \\
\hline R26 & $\mathrm{Cl}+\mathrm{CH}_{4} \rightarrow \mathrm{HCl}+\mathrm{CH}_{3}$ & 1.1 & 150 \\
\hline $\mathrm{R} 27$ & $\mathrm{HCl}+\mathrm{OH} \rightarrow \mathrm{Cl}+\mathrm{H}_{2} \mathrm{O}$ & 1.3 & 100 \\
\hline R28 & $\mathrm{ClO}+\mathrm{NO} \rightarrow \mathrm{Cl}+\mathrm{NO}_{2}$ & 1.15 & 100 \\
\hline $\mathrm{R} 29$ & $\mathrm{H}_{2} \mathrm{O}_{2}+\mathrm{OH} \rightarrow \mathrm{H}_{2} \mathrm{O}+\mathrm{HO}_{2}$ & 1.2 & 100 \\
\hline R30 & $\mathrm{H}_{2}+\mathrm{OH} \rightarrow \mathrm{H}_{2} \mathrm{O}+\mathrm{H}$ & 1.2 & 400 \\
\hline R31 & $\mathrm{N}_{2} \mathrm{O}_{5}+\mathrm{M} \rightarrow \mathrm{NO}_{2}+\mathrm{NO}_{3}+\mathrm{M}$ & 1.3 & 500 \\
\hline R32 & $\mathrm{ClO}+\mathrm{NO}_{2}+\mathrm{M} \rightarrow \mathrm{ClONO}_{2}+\mathrm{M}$ & $3 e-32$ & 1.0 \\
\hline R33 & $\mathrm{H}_{2} \mathrm{O}_{2}+\mathrm{O} \rightarrow \mathrm{HO}_{2}+\mathrm{OH}$ & 2.0 & 1000 \\
\hline $\mathrm{R} 34$ & $\mathrm{HO}_{2}+\mathrm{NO}_{2}+\mathrm{M} \rightarrow \mathrm{HO}_{2} \mathrm{NO}_{2}+\mathrm{M}$ & $3 e-32$ & 0.4 \\
\hline R35 & $\mathrm{ClONO}_{2}+\mathrm{O} \rightarrow \mathrm{ClO}+\mathrm{NO}_{3}$ & 1.5 & 200 \\
\hline $\mathrm{R} 36$ & $\mathrm{HNO}_{3}+\mathrm{OH} \rightarrow \mathrm{NO}_{3}+\mathrm{H}_{2} \mathrm{O}$ & 1.3 & 100 \\
\hline R37 & $\mathrm{NO}+\mathrm{HO}_{2} \rightarrow \mathrm{OH}+\mathrm{NO}_{2}$ & 1.2 & 80 \\
\hline R38 & $\mathrm{H}_{2} \mathrm{O}+\mathrm{O}\left({ }^{1} \mathrm{D}\right) \rightarrow 2 \mathrm{OH}$ & 1.2 & 100 \\
\hline R39 & $\mathrm{OH}+\mathrm{HO}_{2} \rightarrow \mathrm{H}_{2} \mathrm{O}+\mathrm{O}_{2}$ & 1.3 & 200 \\
\hline $\mathrm{R} 40$ & $\mathrm{OH}+\mathrm{O} \rightarrow \mathrm{H}+\mathrm{O}_{2}$ & 1.2 & 100 \\
\hline $\mathrm{R} 41$ & $\mathrm{HO}_{2}+\mathrm{O} \rightarrow \mathrm{OH}+\mathrm{O}_{2}$ & 1.2 & 100 \\
\hline $\mathrm{R} 42$ & $\mathrm{NO}_{2}+\mathrm{O} \rightarrow \mathrm{NO}+\mathrm{O}_{2}$ & 1.1 & 120 \\
\hline $\mathrm{R} 43$ & $\mathrm{NO}_{2}+\mathrm{O}+\mathrm{M} \rightarrow \mathrm{NO}_{3}+\mathrm{M}$ & $1.0 \mathrm{e}-32$ & 1.0 \\
\hline $\mathrm{R} 44$ & $\mathrm{~N}_{2} \mathrm{O}+\mathrm{O}\left({ }^{1} \mathrm{D}\right) \rightarrow 2 \mathrm{NO}$ & 1.3 & 100 \\
\hline $\mathrm{R} 45$ & $\mathrm{NO}_{2}+\mathrm{NO}_{3}+\mathrm{M} \rightarrow \mathrm{N}_{2} \mathrm{O}_{5}+\mathrm{M}$ & $0.5 e-30$ & 1.0 \\
\hline $\mathrm{R} 46$ & $\mathrm{~N}+\mathrm{NO} \rightarrow \mathrm{N}_{2}+\mathrm{O}$ & 1.3 & 100 \\
\hline $\mathrm{R} 47$ & $\mathrm{H} 2+\mathrm{O}\left({ }^{1} \mathrm{D}\right) \rightarrow \mathrm{OH}+\mathrm{H}$ & 1.2 & 100 \\
\hline $\mathrm{R} 48$ & $\mathrm{CH}_{4}+\mathrm{O}\left({ }^{1} \mathrm{D}\right) \rightarrow \mathrm{CH}_{3}+\mathrm{OH}$ & 1.2 & 100 \\
\hline $\mathrm{R} 49$ & $\mathrm{CH}_{3}+\mathrm{O}_{2}+\mathrm{M} \rightarrow \mathrm{CH}_{3} \mathrm{O}_{2}+\mathrm{M}$ & $1.5 \mathrm{E}-31$ & 1.0 \\
\hline R50 & $\mathrm{CH}_{2} \mathrm{O}+\mathrm{OH} \rightarrow \mathrm{H}_{2} \mathrm{O}+\mathrm{HCO}$ & 1.25 & 200 \\
\hline
\end{tabular}


Table 3. (continued)

\begin{tabular}{|c|c|c|c|}
\hline Parameter & Name & $f_{298}$ or $\Delta k_{o}^{300}$ & $\Delta E / R$ or $\Delta n$ \\
\hline R51 & $\mathrm{HCO}+\mathrm{O}_{2} \rightarrow \mathrm{CO}+\mathrm{HO}_{2}$ & 1.3 & 140 \\
\hline R52 & $\mathrm{Cl}+\mathrm{HO}_{2} \rightarrow \mathrm{HCl}+\mathrm{O}_{2}$ & 1.5 & 200 \\
\hline R53 & $\mathrm{CCl}_{4}+\mathrm{O}\left({ }^{1} \mathrm{D}\right) \rightarrow 4 \mathrm{Cl}+$ Products & 1.2 & 100 \\
\hline R54 & $\mathrm{OH}+\mathrm{HO}_{2} \mathrm{NO}_{2} \rightarrow \mathrm{H}_{2} \mathrm{O}+\mathrm{O}_{2}+\mathrm{NO}_{2}$ & 1.5 & 270 \\
\hline R55 & $\mathrm{CH}_{4}+\mathrm{O}\left({ }^{1} \mathrm{D}\right) \rightarrow \mathrm{H}_{2}+\mathrm{CH}_{2} \mathrm{O}$ & 1.2 & 100 \\
\hline $\mathrm{R} 56$ & $\mathrm{OH}+\mathrm{CH}_{3} \mathrm{OOH} \rightarrow \mathrm{H}_{2} \mathrm{O}+\mathrm{CH}_{3} \mathrm{O}_{2}$ & 1.5 & 200 \\
\hline R57 & $\mathrm{OH}+\mathrm{OH} \rightarrow \mathrm{H}_{2} \mathrm{O}+\mathrm{O}$ & 1.4 & 240 \\
\hline $\mathrm{R} 58$ & $\mathrm{ClO}+\mathrm{OH} \rightarrow \mathrm{Cl}+\mathrm{HO}_{2}$ & 1.5 & 150 \\
\hline $\mathrm{R} 59$ & $\mathrm{HOCl}+\mathrm{OH} \rightarrow \mathrm{H}_{2} \mathrm{O}+\mathrm{ClO}$ & 3.0 & 500 \\
\hline $\mathrm{R} 60$ & $\mathrm{Cl}+\mathrm{CH}_{2} \mathrm{O} \rightarrow \mathrm{HCl}+\mathrm{HCO}$ & 1.15 & 100 \\
\hline R61 & $\mathrm{HO}_{2}+\mathrm{HO}_{2}+\mathrm{M} \rightarrow \mathrm{H}_{2} \mathrm{O}_{2}+\mathrm{M}$ & 1.3 & 400 \\
\hline $\mathrm{R} 62$ & $\mathrm{CFClO}+\mathrm{O}\left({ }^{1} \mathrm{D}\right) \rightarrow$ Products & 2.0 & 100 \\
\hline R63 & $\mathrm{CF}_{2} \mathrm{O}+\mathrm{O}\left({ }^{1} \mathrm{D}\right) \rightarrow$ Products & 2.0 & 100 \\
\hline $\mathrm{R} 64$ & $\mathrm{Cl}+\mathrm{HO}_{2} \rightarrow \mathrm{OH}+\mathrm{ClO}$ & 2.0 & 200 \\
\hline R65 & $\mathrm{BrO}+\mathrm{NO} \rightarrow \mathrm{NO}_{2}+\mathrm{Br}$ & 1.15 & 130 \\
\hline R66 & $\mathrm{HO}_{2} \mathrm{NO}_{2}+\mathrm{M} \rightarrow \mathrm{HO}_{2}+\mathrm{NO}_{2}+\mathrm{M}$ & 5.0 & 1000 \\
\hline R67 & $\mathrm{NO}+\mathrm{NO}_{3} \rightarrow 2 \mathrm{NO}_{2}$ & 1.3 & 100 \\
\hline R68 & $\mathrm{OH}+\mathrm{CH}_{3} \mathrm{CCl}_{3} \rightarrow 3 \mathrm{Cl}+$ Products & 1.1 & 150 \\
\hline R69 & $\mathrm{NO}+\mathrm{O}+\mathrm{M} \rightarrow \mathrm{NO}_{2}+\mathrm{M}$ & $2.0 \mathrm{e}-32$ & 0.3 \\
\hline R70 & $\mathrm{N}_{2} \mathrm{O}+\mathrm{O}\left({ }^{1} \mathrm{D}\right) \rightarrow \mathrm{N}_{2}+\mathrm{O}_{2}$ & 1.3 & 100 \\
\hline $\mathrm{R} 71$ & $\mathrm{CF}_{2} \mathrm{Cl}_{2}+\mathrm{O}\left({ }^{1} \mathrm{D}\right) \rightarrow \mathrm{ClO}+\mathrm{Cl}+\mathrm{Frag}$ & 1.3 & 100 \\
\hline $\mathrm{R} 72$ & $\mathrm{~N}+\mathrm{NO}_{2} \rightarrow \mathrm{N}_{2} \mathrm{O}+\mathrm{O}$ & 1.5 & 100. \\
\hline R73 & $\mathrm{CFCl}_{3}+\mathrm{O}\left({ }^{1} \mathrm{D}\right) \rightarrow \mathrm{ClO}+2 \mathrm{Cl}+\mathrm{Frag}$ & 1.2 & 100 \\
\hline R74 & $\mathrm{O}_{2}+\mathrm{O}_{2}\left({ }^{1} \mathrm{D}\right) \rightarrow 2 \mathrm{O}_{2}$ & 1.2 & 100 \\
\hline $\mathrm{R} 75$ & $\mathrm{O}_{3}+\mathrm{O}_{2}\left({ }^{1} \mathrm{D}\right) \rightarrow 2 \mathrm{O}_{2}+\mathrm{O}$ & 1.2 & 500 \\
\hline
\end{tabular}


Table 3. (continued)

\begin{tabular}{|c|c|c|c|}
\hline Parameter & Name & $f_{298}$ or $\Delta k_{o}^{300}$ & $\Delta E / R$ or $\Delta n$ \\
\hline R76 & $\mathrm{Br}+\mathrm{O}_{3} \rightarrow \mathrm{BrO}+\mathrm{O}_{2}$ & 1.2 & 200 \\
\hline R77 & $\mathrm{Br}+\mathrm{HO}_{2} \rightarrow \mathrm{HBr}+\mathrm{O}_{2}$ & 2.0 & 600 \\
\hline R78 & $\mathrm{BrO}+\mathrm{ClO} \rightarrow \mathrm{Br}+\mathrm{ClOO}$ & 1.25 & 200 \\
\hline R79 & $\mathrm{BrO}+\mathrm{BrO} \rightarrow 2 \mathrm{Br}+\mathrm{O}_{2}$ & 1.25 & 150 \\
\hline $\mathrm{R} 80$ & $\mathrm{OH}+\mathrm{HBr} \rightarrow \mathrm{H}_{2} \mathrm{O}+\mathrm{Br}$ & 1.2 & 250 \\
\hline $\mathrm{R} 81$ & $\mathrm{BrO}+\mathrm{NO}_{2}+\mathrm{M} \rightarrow \mathrm{BrONO}_{2}+\mathrm{M}$ & $0.6 \mathrm{e}-31$ & 0.8 \\
\hline $\mathrm{R} 82$ & $\mathrm{CH}_{3} \mathrm{Br}+\mathrm{OH} \rightarrow \mathrm{Br}+$ Products & 1.1 & 150 \\
\hline $\mathrm{R} 83$ & $\mathrm{CHClF}_{2}+\mathrm{OH} \rightarrow \mathrm{Cl}+2 \mathrm{f}+$ Products & 1.1 & 150 \\
\hline $\mathrm{R} 84$ & $\mathrm{C}_{2} \mathrm{Cl}_{3} \mathrm{~F}_{3}+\mathrm{O}\left({ }^{1} \mathrm{D}\right) \rightarrow 3 \mathrm{Cl}+$ Products & 2.0 & 100 \\
\hline $\mathrm{R} 85$ & $\mathrm{C}_{2} \mathrm{Cl}_{2} \mathrm{~F}_{4}+\mathrm{O}\left({ }^{1} \mathrm{D}\right) \rightarrow 2 \mathrm{Cl}+4 \mathrm{f}+$ Products & 2.0 & 100 \\
\hline $\mathrm{R} 86$ & $\mathrm{C}_{2} \mathrm{ClF}_{5}+\mathrm{O}\left({ }^{1} \mathrm{D}\right) \rightarrow \mathrm{Cl}+5 \mathrm{f}+$ Products & 1.3 & 100 \\
\hline $\mathrm{R} 87$ & $\mathrm{ClO}+\mathrm{ClO}+\mathrm{M} \rightarrow \mathrm{Cl}_{2} \mathrm{O}_{2}+\mathrm{M}$ & $0.4 \mathrm{E}-32$ & 0.5 \\
\hline $\mathrm{R} 88$ & $\mathrm{BrO}+\mathrm{ClO} \rightarrow \mathrm{Br}+\mathrm{OClO}$ & 1.25 & 200 \\
\hline $\mathrm{R} 89$ & $\mathrm{BrO}+\mathrm{ClO} \rightarrow \mathrm{BrCl}+\mathrm{O}_{2}$ & 1.25 & 200 \\
\hline $\mathrm{R} 90$ & $\mathrm{BrO}+\mathrm{O} \rightarrow \mathrm{Br}+\mathrm{O}_{2}$ & 1.5 & 150 \\
\hline R91 & $\mathrm{BrO}+\mathrm{HO}_{2} \rightarrow \mathrm{HOBr}+\mathrm{O}_{2}$ & 1.5 & 500 \\
\hline R92 & $\mathrm{Br}+\mathrm{CH}_{2} \mathrm{O} \rightarrow \mathrm{HBr}+\mathrm{CHO}$ & 1.3 & 200 \\
\hline R93 & $\mathrm{CH}_{4}+\mathrm{O}\left({ }^{1} \mathrm{D}\right) \rightarrow \mathrm{H}+\mathrm{CH}_{3} \mathrm{O}$ & 1.2 & 100 \\
\hline
\end{tabular}


Table 2. Photolytic decomposition rates varied in Monte Carlo runs.

\begin{tabular}{|c|c|c|}
\hline Parameter & Name & Uncertainty \\
\hline $\mathrm{J} 1$ & $\mathrm{O}_{2} \rightarrow \mathrm{O}+\mathrm{O}$ & 1.20 \\
\hline $\mathrm{J} 2$ & $\mathrm{O}_{3} \rightarrow \mathrm{O}_{2}+\mathrm{O}\left({ }^{1} \mathrm{D}\right)$ & 1.25 \\
\hline $\mathrm{J} 3$ & $\mathrm{O}_{3} \rightarrow \mathrm{O}_{2}+\mathrm{O}$ & 1.10 \\
\hline $\mathrm{J} 4$ & $\mathrm{H}_{2} \mathrm{O} \rightarrow \mathrm{H}+\mathrm{OH}$ & 1.20 \\
\hline $\mathrm{J} 5$ & $\mathrm{NO}_{3} \rightarrow \mathrm{NO}_{2}+\mathrm{O}$ & 2.00 \\
\hline J6 & $\mathrm{HNO}_{3} \rightarrow \mathrm{OH}+\mathrm{NO}_{2}$ & 1.30 \\
\hline $\mathrm{J} 7$ & $\mathrm{NO}_{2} \rightarrow \mathrm{NO}+\mathrm{O}$ & 1.20 \\
\hline $\mathrm{J} 8$ & $\mathrm{H}_{2} \mathrm{O}_{2} \rightarrow 2 \mathrm{OH}$ & 1.30 \\
\hline $\mathrm{J9}$ & $\mathrm{N}_{2} \mathrm{O}_{5} \rightarrow \mathrm{NO}_{2}+\mathrm{NO}_{3}$ & 2.00 \\
\hline $\mathrm{J} 10$ & $\mathrm{CH}_{2} \mathrm{O} \rightarrow \mathrm{HCO}+\mathrm{H}$ & 1.20 \\
\hline $\mathrm{J} 11$ & $\mathrm{CH}_{2} \mathrm{O} \rightarrow \mathrm{H}_{2}+\mathrm{CO}$ & 1.20 \\
\hline $\mathrm{J} 12$ & $\mathrm{CO}_{2} \rightarrow \mathrm{CO}+\mathrm{O}$ & 1.20 \\
\hline $\mathrm{J} 13$ & $\mathrm{CH}_{3} \mathrm{OOH} \rightarrow \mathrm{CH}_{3} \mathrm{O}+\mathrm{OH}$ & 1.50 \\
\hline $\mathrm{J} 14$ & $\mathrm{~N}_{2} \mathrm{O} \rightarrow \mathrm{N}_{2}+\mathrm{O}$ & 1.20 \\
\hline $\mathrm{J} 15$ & $\mathrm{ClONO}_{2} \rightarrow \mathrm{Cl}+\mathrm{NO}_{3}$ & 1.30 \\
\hline $\mathrm{J} 16$ & $\mathrm{NO} \rightarrow \mathrm{N}+\mathrm{O}$ & 1.20 \\
\hline $\mathrm{J} 17$ & $\mathrm{NO}_{3} \rightarrow \mathrm{NO}+\mathrm{O}_{2}$ & 1.30 \\
\hline $\mathrm{J} 18$ & $\mathrm{HCl} \rightarrow \mathrm{H}+\mathrm{Cl}$ & 1.10 \\
\hline $\mathrm{J} 19$ & $\mathrm{CCl}_{4} \rightarrow 4 \mathrm{Cl}+$ Fragment & 1.10 \\
\hline $\mathrm{J} 20$ & $\mathrm{CH}_{3} \mathrm{Cl} \rightarrow \mathrm{CH}_{3}+\mathrm{Cl}$ & 1.10 \\
\hline $\mathrm{J} 21$ & $\mathrm{CFCl}_{3} \rightarrow 3 \mathrm{Cl}+$ Fragment & 1.10 \\
\hline $\mathrm{J} 22$ & $\mathrm{CF}_{2} \mathrm{Cl}_{2} \rightarrow 2 \mathrm{Cl}+$ Fragment & 1.10 \\
\hline $\mathrm{J} 23$ & $\mathrm{HOCl} \rightarrow \mathrm{OH}+\mathrm{Cl}$ & 1.40 \\
\hline $\mathrm{J} 24$ & $\mathrm{HO}_{2} \mathrm{NO}_{2} \rightarrow \mathrm{OH}+\mathrm{NO}_{3}$ & 2.00 \\
\hline $\mathrm{J} 25$ & $\mathrm{H}_{2} \mathrm{O} \rightarrow \mathrm{H}_{2}+\mathrm{O}\left({ }^{1} \mathrm{D}\right)$ & 1.20 \\
\hline
\end{tabular}


Table 2. (continued)

\begin{tabular}{|c|c|c|}
\hline Parameter & Name & Uncertainty \\
\hline $\mathrm{J} 26$ & $\mathrm{CH}_{3} \mathrm{CCl}_{3} \rightarrow 3 \mathrm{Cl}+$ Fragment & 1.20 \\
\hline $\mathrm{J} 27$ & $\mathrm{BrO} \rightarrow \mathrm{Br}+\mathrm{O}$ & 1.20 \\
\hline $\mathrm{J} 28$ & $\mathrm{BrONO}_{2} \rightarrow \mathrm{Br}+\mathrm{NO}_{3}$ & 1.40 \\
\hline $\mathrm{J} 29$ & $\mathrm{CH}_{3} \mathrm{Br} \rightarrow \mathrm{CH}_{3}+\mathrm{Br}$ & 1.20 \\
\hline $\mathrm{J} 30$ & $\mathrm{CF}_{3} \mathrm{Br} \rightarrow \mathrm{Br}+3 \mathrm{~F}+$ Fragment & 1.30 \\
\hline $\mathrm{J} 31$ & $\mathrm{CF}_{2} \mathrm{ClBr} \rightarrow \mathrm{Br}+\mathrm{Cl}+2 \mathrm{f}+$ Fragment & 2.00 \\
\hline $\mathrm{J} 32$ & $\mathrm{CHClF}_{2} \rightarrow \mathrm{Cl}+2 \mathrm{f}+$ Fragment & 1.20 \\
\hline $\mathrm{J} 33$ & $\mathrm{C}_{2} \mathrm{Cl}_{3} \mathrm{~F}_{3} \rightarrow 3 \mathrm{Cl}+3 \mathrm{f}+$ Fragment & 1.20 \\
\hline J34 & $\mathrm{C}_{2} \mathrm{Cl}_{2} \mathrm{~F}_{4} \rightarrow 2 \mathrm{Cl}+4 \mathrm{f}+$ Fragment & 1.20 \\
\hline J35 & $\mathrm{C}_{2} \mathrm{ClF}_{5} \rightarrow \mathrm{Cl}+5 \mathrm{f}+$ Fragment & 1.20 \\
\hline J36 & $\mathrm{Cl}_{2} \mathrm{O}_{2} \rightarrow \mathrm{Cl}+\mathrm{ClOO}$ & 1.20 \\
\hline $\mathrm{J} 37$ & $\mathrm{BrCl} \rightarrow \mathrm{Br}+\mathrm{Cl}$ & 1.20 \\
\hline J38 & $\mathrm{CO}_{2} \rightarrow \mathrm{CO}+\mathrm{O}\left({ }^{1} \mathrm{D}\right)$ & 1.20 \\
\hline J39 & $\mathrm{HO}_{2} \mathrm{NO}_{2} \rightarrow \mathrm{HO}_{2}+\mathrm{NO}_{2}$ & 2.00 \\
\hline $\mathrm{J} 40$ & $\mathrm{CClFO} \rightarrow \mathrm{Cl}+\mathrm{f}+$ Fragment & 1.20 \\
\hline $\mathrm{J} 41$ & $\mathrm{CF}_{2} \mathrm{O} \rightarrow 2 \mathrm{f}+$ Fragment & 1.30 \\
\hline $\mathrm{J} 42$ & $\mathrm{CH}_{4} \rightarrow \mathrm{CH}_{3}+\mathrm{H}$ & 1.20 \\
\hline $\mathrm{J} 43$ & $\mathrm{CH}_{4} \rightarrow \mathrm{CH}_{2}+\mathrm{H}_{2}$ & 1.20 \\
\hline $\mathrm{J} 44$ & $\mathrm{CH}_{4} \rightarrow \mathrm{CH}+\mathrm{H}+\mathrm{H}_{2}$ & 1.20 \\
\hline $\mathrm{J} 45$ & $\mathrm{CH}_{3} \mathrm{O}_{2} \rightarrow \mathrm{CH}_{3}+\mathrm{O}_{2}$ & 1.20 \\
\hline
\end{tabular}


Table 3. Heterogeneous reaction parameters varied in Monte Carlo runs.

\begin{tabular}{|c|c|c|}
\hline Parameter & Name & Uncertainty \\
\hline $\mathrm{H} 1$ & $\mathrm{ClONO}_{2}+\mathrm{HCl} \rightarrow \mathrm{HNO}_{3}+\mathrm{Cl}_{2}$ (sulf) & $5^{a}$ \\
\hline $\mathrm{H} 2$ & $\mathrm{ClONO}_{2}+\mathrm{H}_{2} \mathrm{O} \rightarrow \mathrm{HNO}_{3}+\mathrm{HOCl}$ (sulf) & $3^{a}$ \\
\hline H3 & $\mathrm{N}_{2} \mathrm{O}_{5}+\mathrm{H}_{2} \mathrm{O} \rightarrow 2 \mathrm{HNO}_{3}$ (sulf) & 2 \\
\hline $\mathrm{H} 4$ & $\mathrm{HOCl}+\mathrm{HCl} \rightarrow \mathrm{H}_{2} \mathrm{O}+\mathrm{Cl}_{2}$ (sulf) & $3^{b}$ \\
\hline $\mathrm{H} 5$ & $\mathrm{BrONO}_{2}+\mathrm{H}_{2} \mathrm{O} \rightarrow \mathrm{HNO}_{3}+\mathrm{HOBr}$ (sulf) & $2^{c}$ \\
\hline $\mathrm{H} 6$ & $\mathrm{HOBr}+\mathrm{HCl} \rightarrow \mathrm{H}_{2} \mathrm{O}+\mathrm{BrCl}$ (sulf) & $3^{c}$ \\
\hline $\mathrm{H} 7$ & $\mathrm{ClONO}_{2}+\mathrm{HCl} \rightarrow \mathrm{HNO}_{3}+\mathrm{Cl}_{2}$ (nat) & 3 \\
\hline H8 & $\mathrm{ClONO}_{2}+\mathrm{H}_{2} \mathrm{O} \rightarrow \mathrm{HNO}_{3}+\mathrm{HOCl}$ (nat) & $10^{a}$ \\
\hline H9 & $\mathrm{N}_{2} \mathrm{O}_{5}+\mathrm{H}_{2} \mathrm{O} \rightarrow 2 \mathrm{HNO}_{3}$ (nat) & 3 \\
\hline $\mathrm{H} 10$ & $\mathrm{~N}_{2} \mathrm{O}_{5}+\mathrm{HCl} \rightarrow \mathrm{HNO}_{3}+\mathrm{ClONO}$ (nat) & 2 \\
\hline $\mathrm{H} 11$ & $\mathrm{HOCl}+\mathrm{HCl} \rightarrow \mathrm{H}_{2} \mathrm{O}+\mathrm{Cl}_{2}$ (nat) & 3 \\
\hline $\mathrm{H} 12$ & $\mathrm{ClONO}_{2}+\mathrm{HCl} \rightarrow \mathrm{HNO}_{3}+\mathrm{Cl}_{2}$ (ice) & $2^{b}$ \\
\hline $\mathrm{H} 13$ & $\mathrm{ClONO}_{2}+\mathrm{H}_{2} \mathrm{O} \rightarrow \mathrm{HNO}_{3}+\mathrm{HOCl}$ (ice) & 10 \\
\hline $\mathrm{H} 14$ & $\mathrm{~N}_{2} \mathrm{O}_{5}+\mathrm{H}_{2} \mathrm{O} \rightarrow 2 \mathrm{HNO}_{3}$ (ice) & 3 \\
\hline $\mathrm{H} 15$ & $\mathrm{HOCl}+\mathrm{HCl} \rightarrow \mathrm{H}_{2} \mathrm{O}+\mathrm{Cl}_{2}$ (ice) & 3 \\
\hline $\mathrm{H} 16$ & $\mathrm{HOBr}+\mathrm{HCl} \rightarrow \mathrm{H}_{2} \mathrm{O}+\mathrm{BrCl}$ (ice) & 3 \\
\hline $\mathrm{H} 17$ & Type 1 (nat) mode radius & $2^{d}$ \\
\hline $\mathrm{H} 18$ & Type 2 (ice) mode radius & $2^{d}$ \\
\hline H19 & Supersaturation ratio (nat) & $2^{e}$ \\
\hline $\mathrm{H} 20$ & Supersaturation ratio (ice) & $1.2^{e}$ \\
\hline
\end{tabular}

${ }^{a}$ Chosen on basis of DeMore et al. [1994] Table 59 notes.

${ }^{b}$ D. R. Hanson, personal communication, 1996.

${ }^{c}$ Based on Hanson and Ravishankara, [1995].

${ }^{d}$ Personal judgement of uncertainty.

${ }^{e}$ Corresponds to $1 \mathrm{~K}$ uncertainty in supersaturation temperature. 


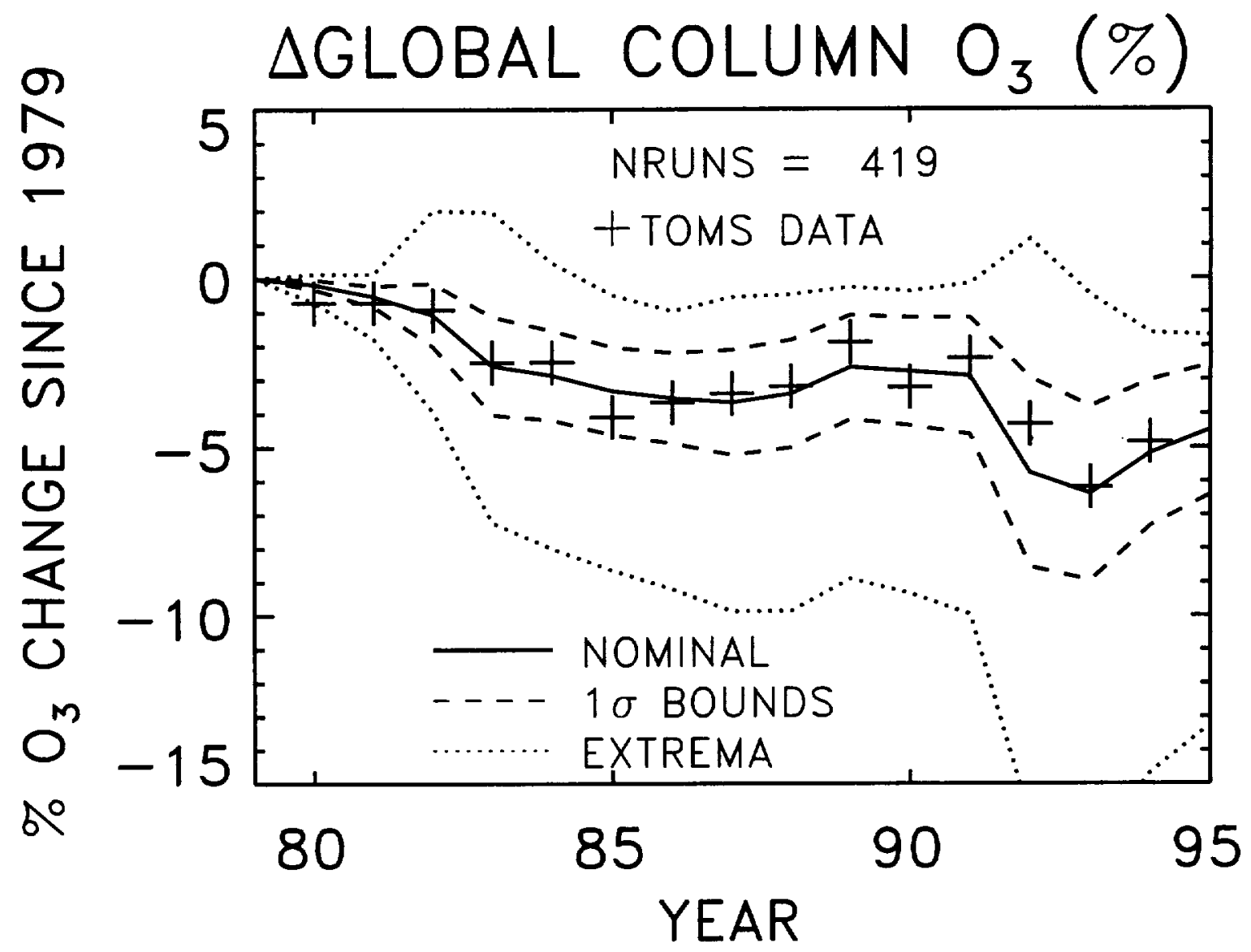

Figure 1 


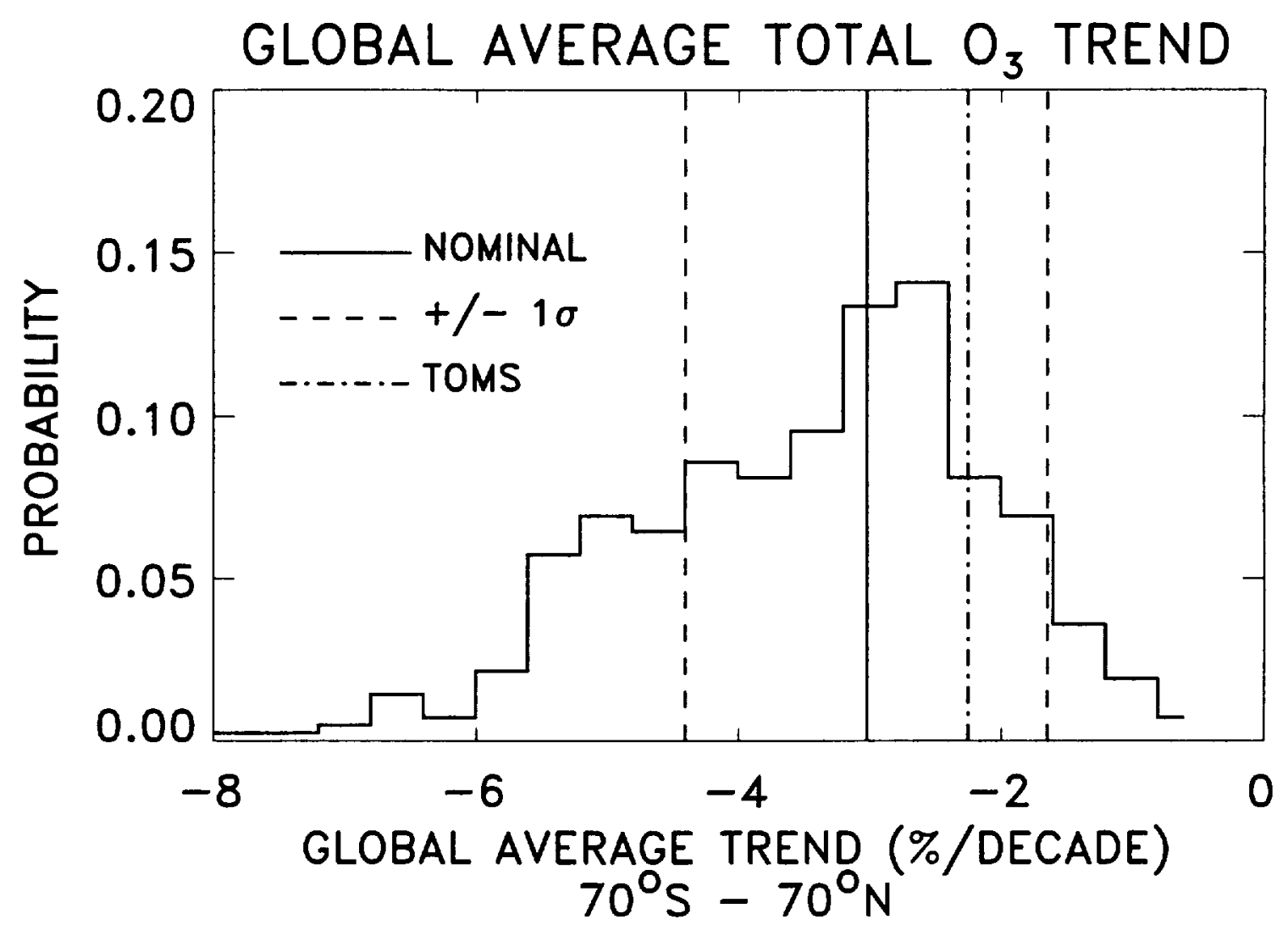

Figure 2 

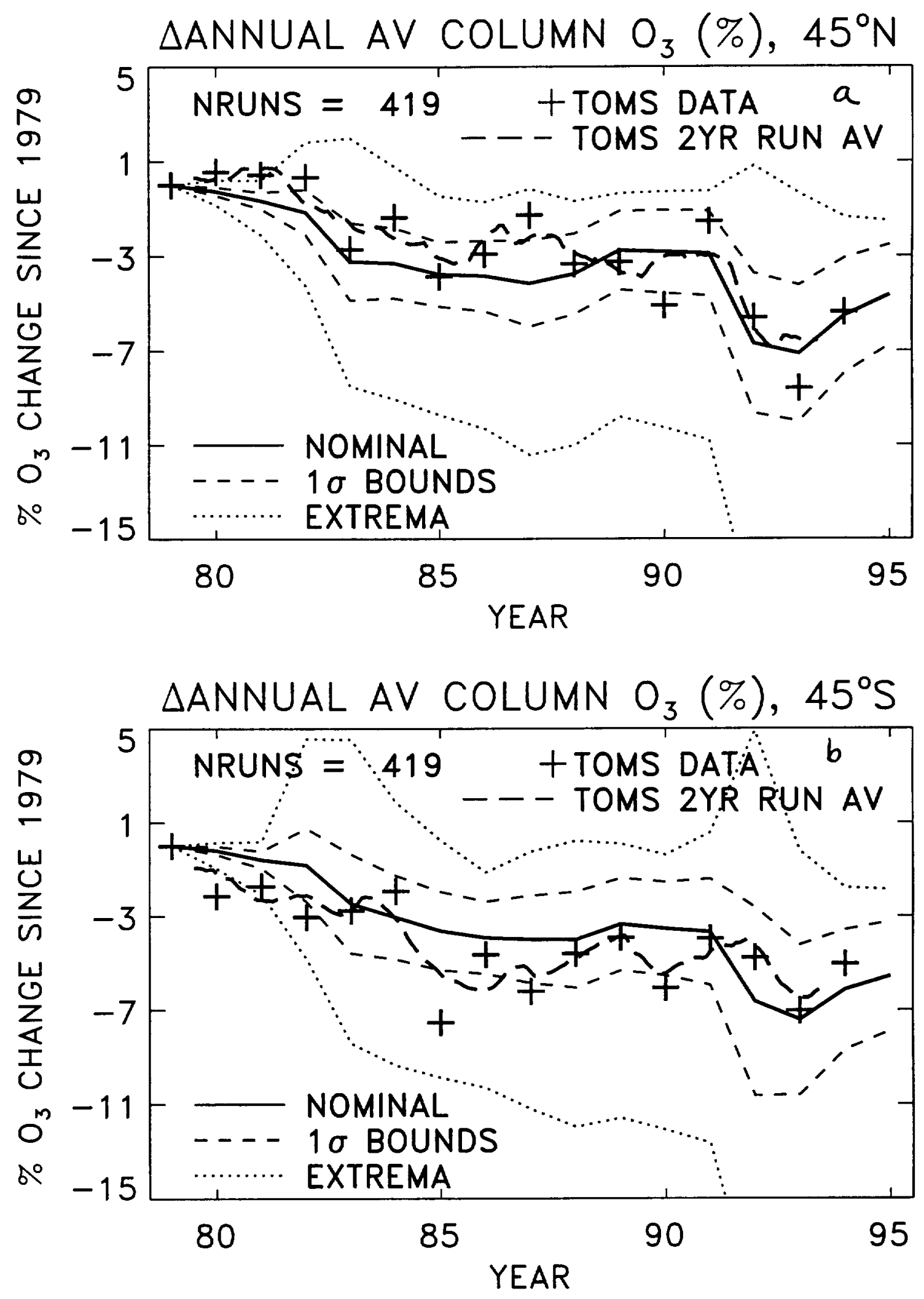

Figure 3 


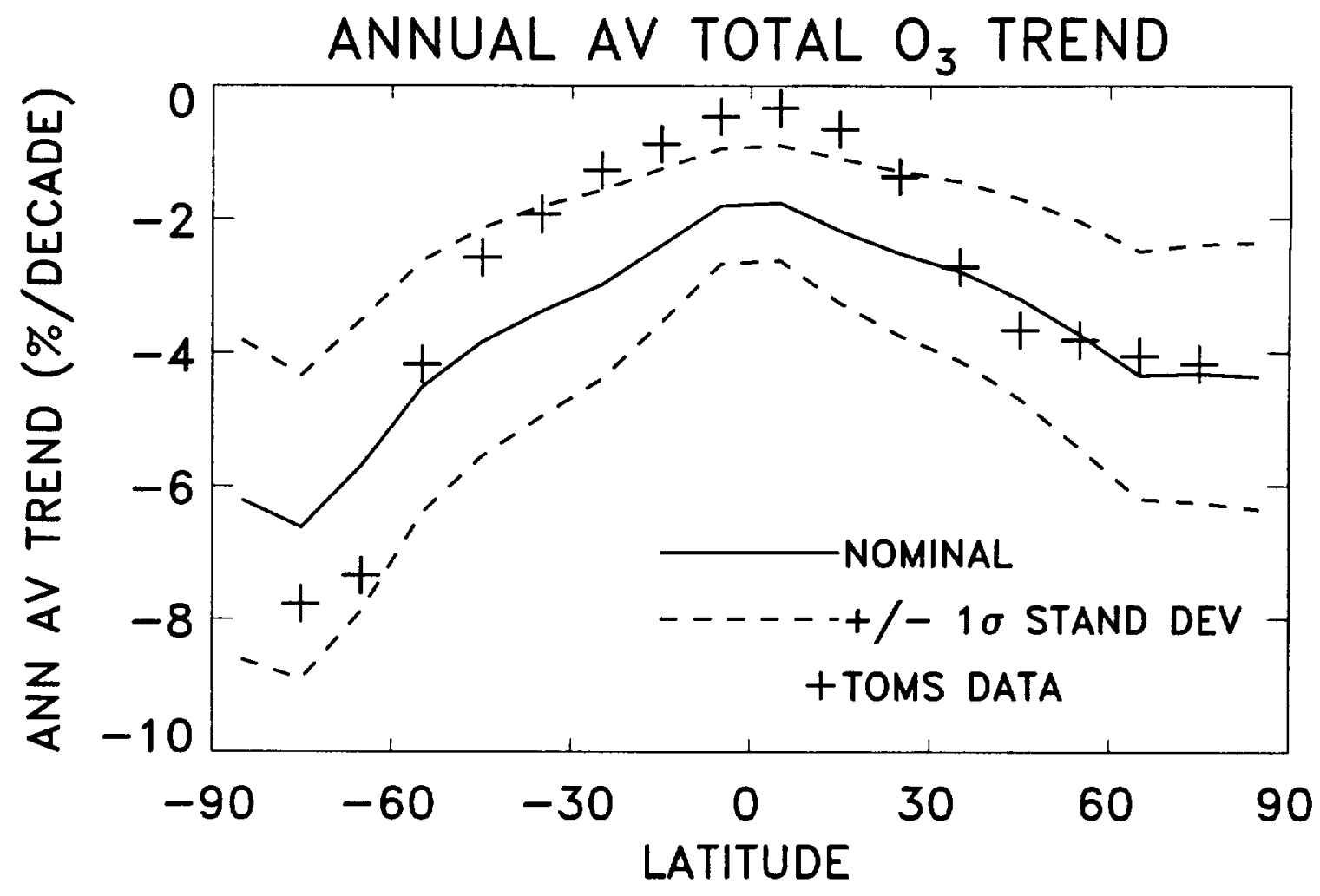

Figure 4 


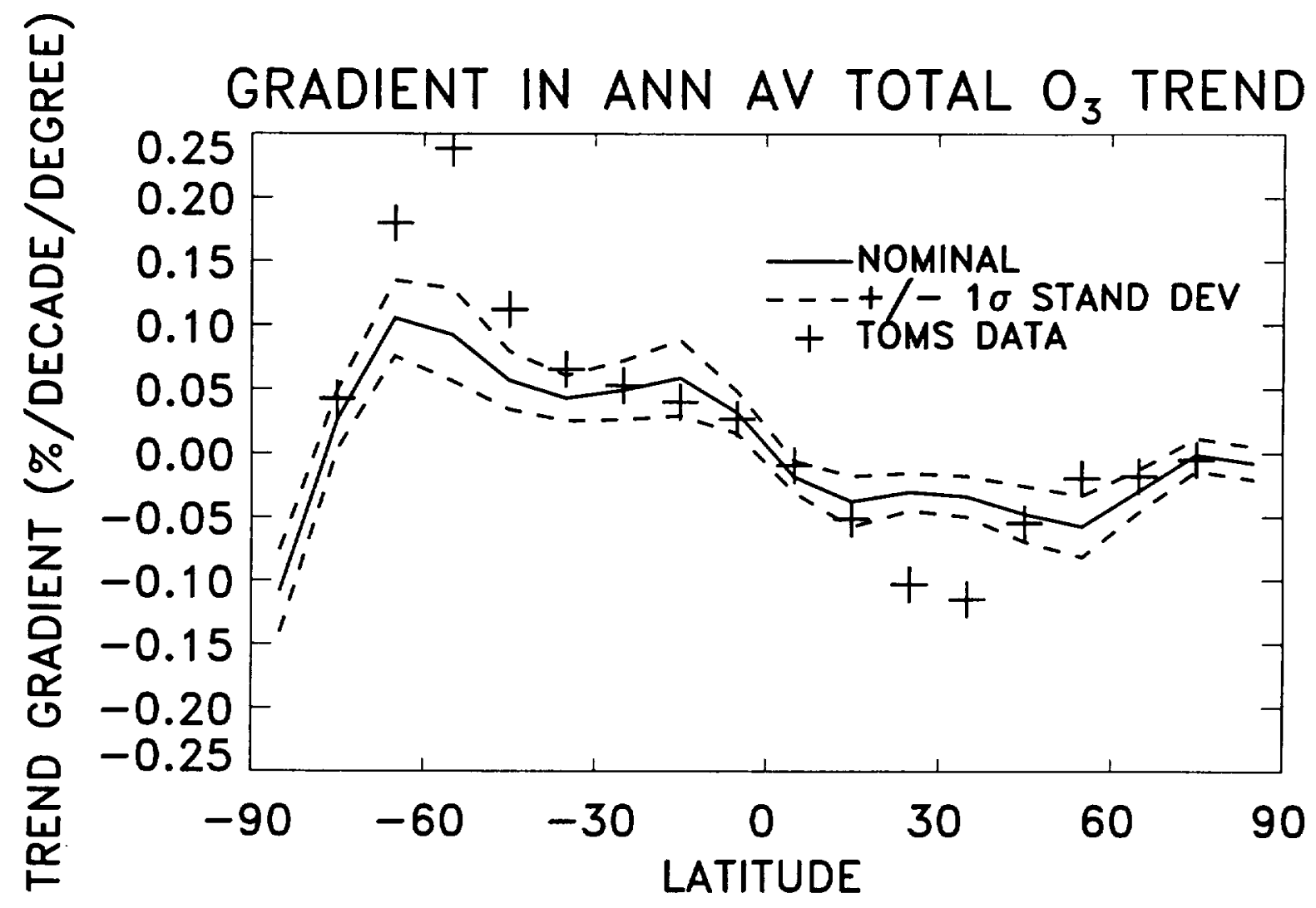

Figure 5 


\section{V7 TOMS TREND (\%/DECADE)}

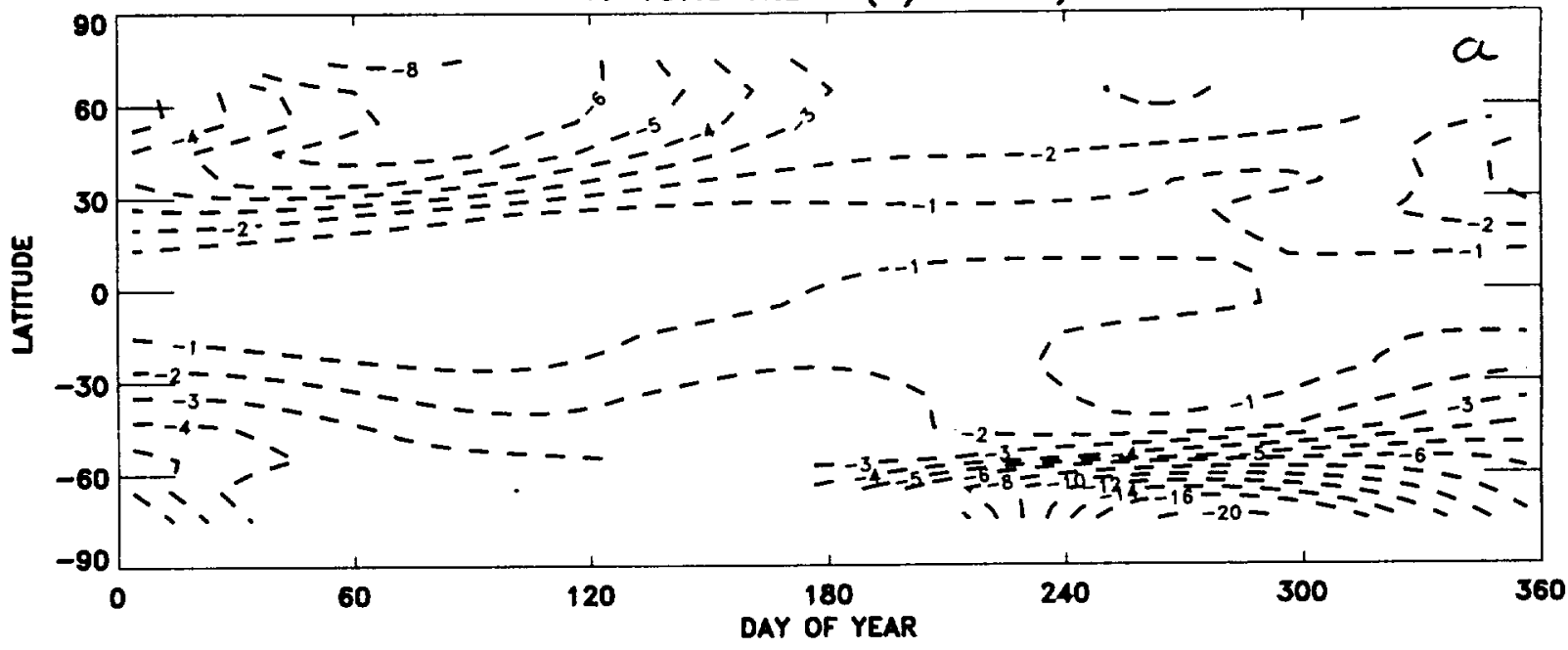

GSFC 20 MODEL NOMINAL TREND (\%/DECADE)

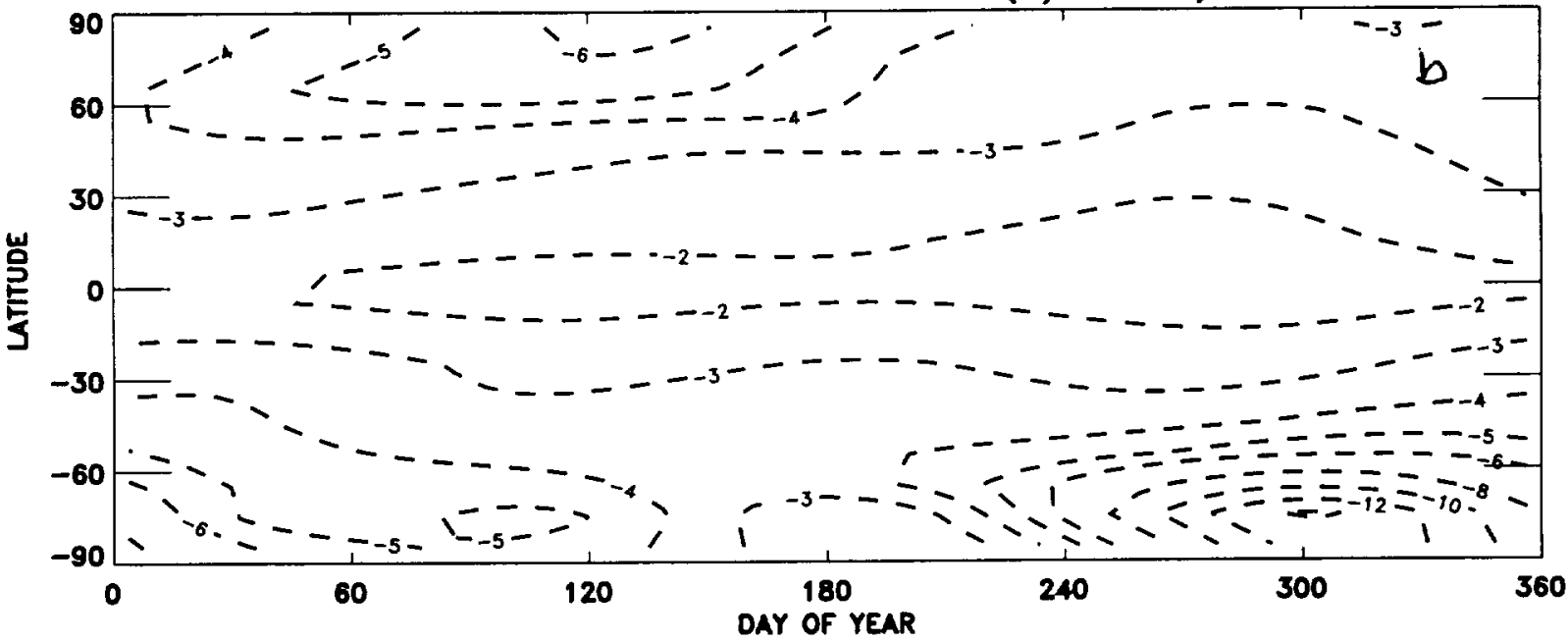

$1 \sigma$ TREND UNCERTAINTY (\%/DECADE)

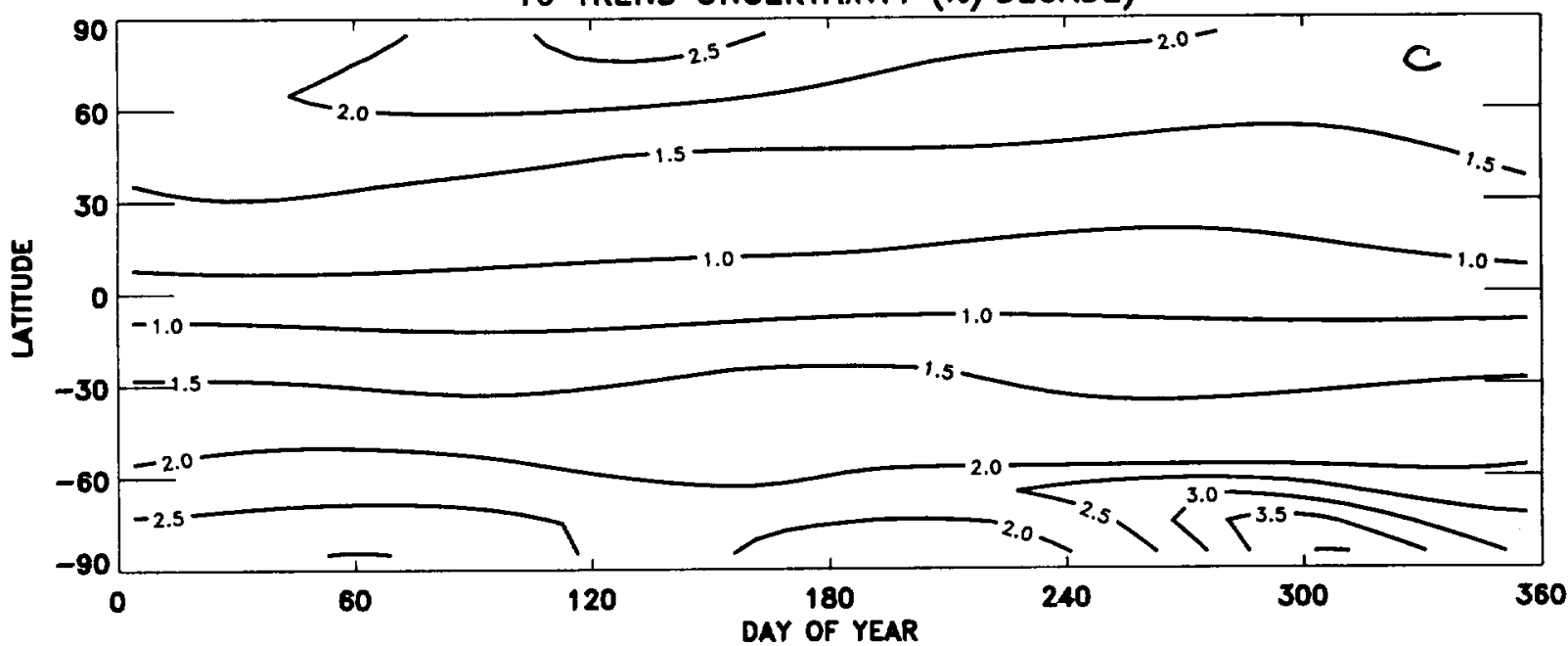

Figure 6 


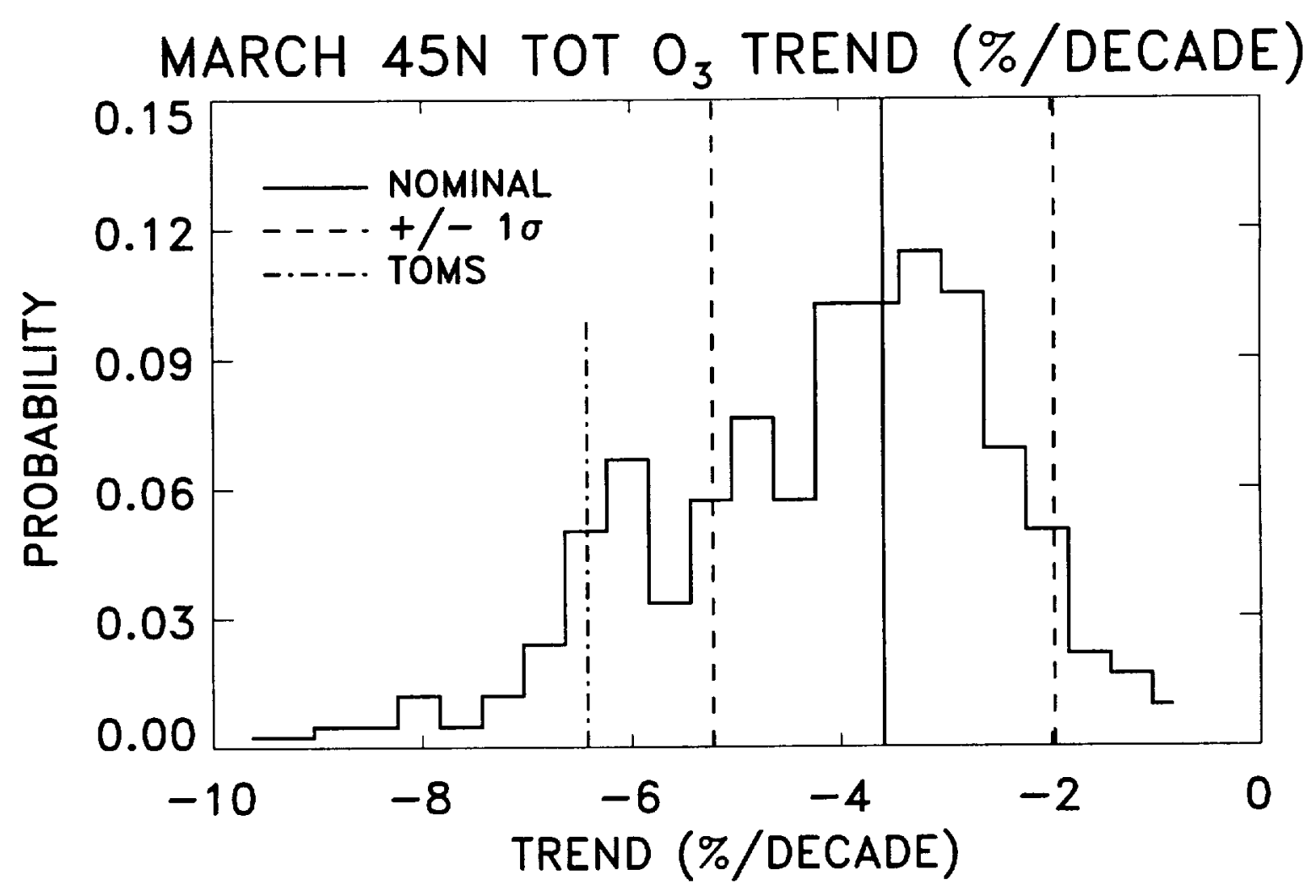

Figure 7 


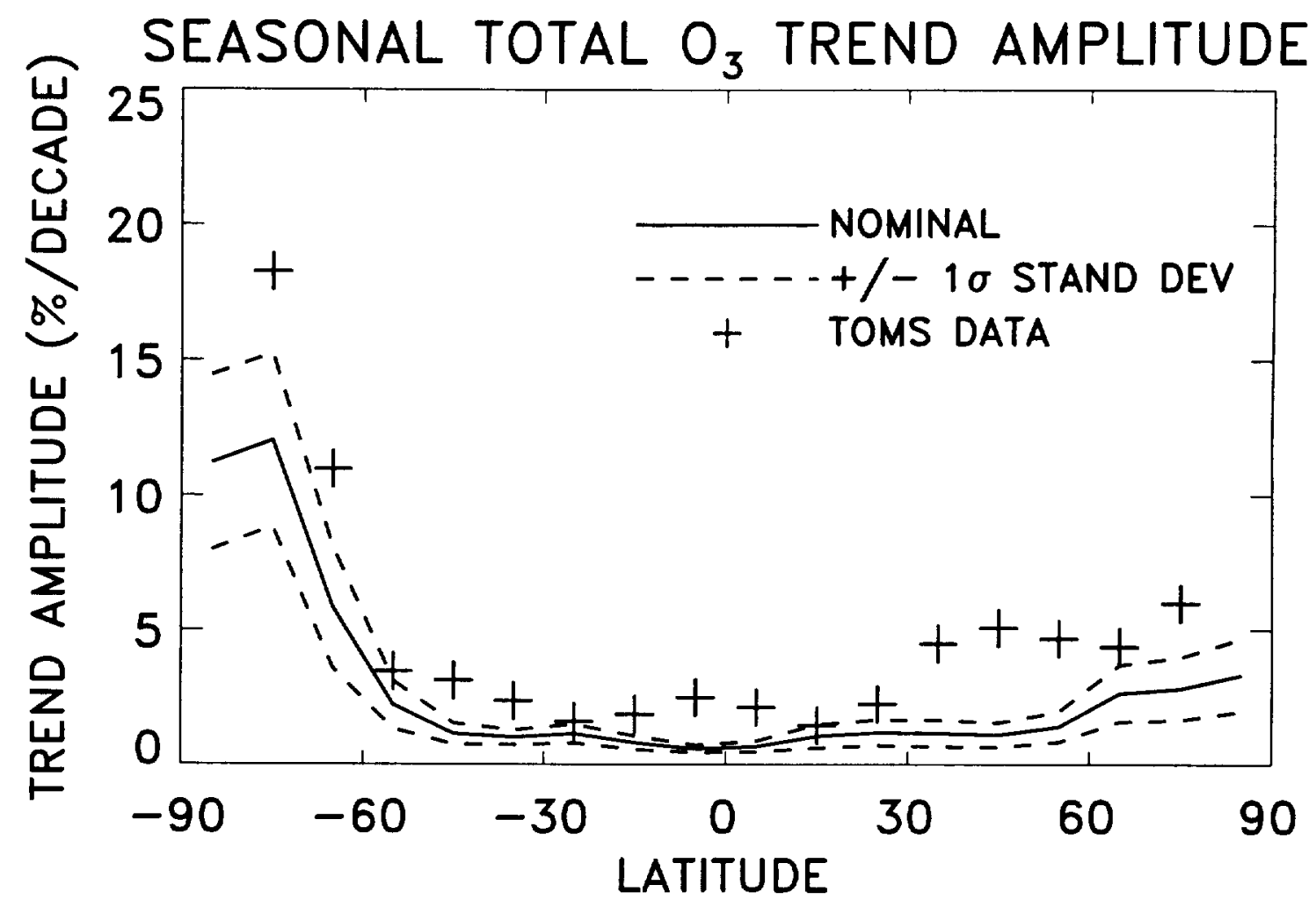

Figure 8 


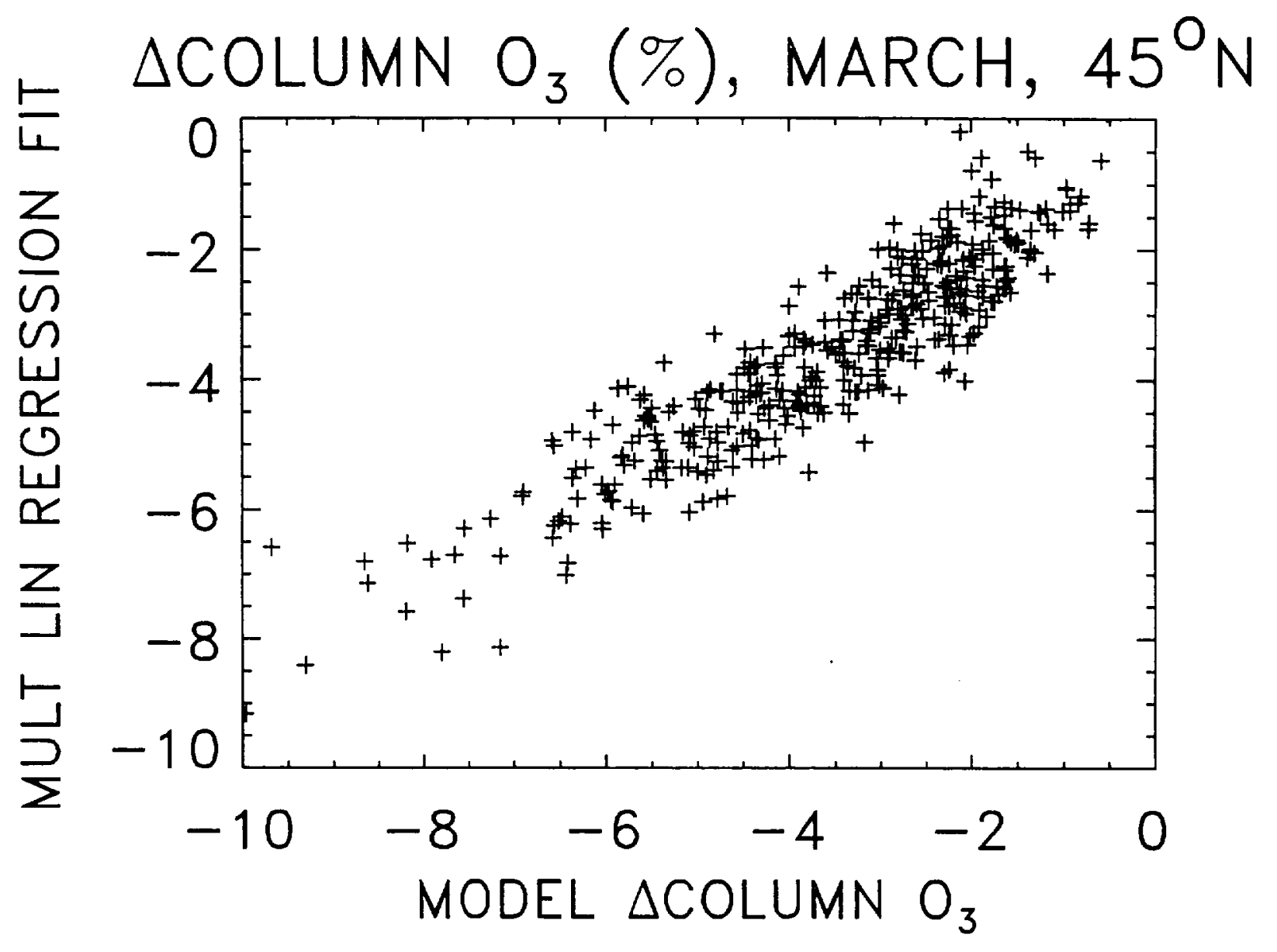

Figure 9 